\title{
Development of a Computational Platform for Methane-Induced Vented Explosions
}

Francis R. Kronz III

Follow this and additional works at: https://researchrepository.wvu.edu/etd

\section{Recommended Citation}

Kronz III, Francis R., "Development of a Computational Platform for Methane-Induced Vented Explosions" (2016). Graduate Theses, Dissertations, and Problem Reports. 6017.

https://researchrepository.wvu.edu/etd/6017

This Thesis is protected by copyright and/or related rights. It has been brought to you by the The Research Repository @ WVU with permission from the rights-holder(s). You are free to use this Thesis in any way that is permitted by the copyright and related rights legislation that applies to your use. For other uses you must obtain permission from the rights-holder(s) directly, unless additional rights are indicated by a Creative Commons license in the record and/ or on the work itself. This Thesis has been accepted for inclusion in WVU Graduate Theses, Dissertations, and Problem Reports collection by an authorized administrator of The Research Repository @ WVU. For more information, please contact researchrepository@mail.wvu.edu. 
Development of a Computational Platform for Methane-Induced Vented Explosions

Francis R. Kronz III

Thesis submitted to the

Benjamin M. Statler College of Engineering and Mineral Resources at West Virginia University

in partial fulfillment of the requirements for the degree of

Master of Science

in

Aerospace Engineering

V'yacheslav Akkerman, Ph.D., Chair

Arvind Thiruvengatam, Ph.D

Jérôme Taveau

Department of Mechanical and Aerospace Engineering

West Virginia University

Morgantown, West Virginia

2016

Keywords:

vented explosions, enclosures, methane, EVA, overpressures

Copyright 2016 Francis R Kronz III 


\section{Abstract \\ Development of a Computational Platform for Methane-Induced Vented Explosions Francis R. Kronz III}

Accidental expositions in enclosures, such as industrial and residential buildings, lead to a pressure rise that may injure or kill the personnel as well as damage the construction. For example, an overpressure as small as $\sim 0.1$ atm is enough to kill a person or break glass items, while $\sim 1$ atm overpressures may crucially destroy the structure, including collapsing the walls. A standard remedy strategy against such a disaster is employing venting areas such as windows to allow the expanding gas to escape and thereby reducing the maximal overpressure. There are two common ways how to predict the pressure rise in an enclosure for a given vent size; location and geometry. Namely, either phenomenological models, identified from particular experiments, or those from the comprehensive computational fluid dynamics (CFD) are usually used. However, there is a certain gap between these two approaches. Phenomenological models are simple but less accurate and while CFD models, despite being more accurate, are often too computationally expensive and complex to employ, promptly, in any situation. There is therefore a critical need to reduce such a gap by establishing a simple but viable computational model that will imitate the experiments from the practical reality with an acceptable level of accuracy.

This thesis is a step in developing such a computational explosive vent analyzer (EVA). Specifically, the EVA calculates the initial overpressure in an enclosure for a given vent size, equivalence ratio, enclosure geometry and breaking pressure of the vent cover if necessary. The computational platform is designed to be computationally inexpensive and simple in that it is easy to learn, employ and modify for different situations. The results obtained are generated for near-stoichiometric, methane-air explosions for the venting area of $2.7 \mathrm{~m}^{2}$ and $5.4 \mathrm{~m}^{2}$, with a central or rear ignition. These results are validated by the experimental and computational data from the literature, with good qualitative and quantitative agreement shown. It is demonstrated that the EVA can predict the timing and magnitude of the overpressure in the experiments with accuracy comparable to the best CFD models in the field. Parametric studies are discussed for various vent areas and equivalence ratios. 


\section{Acknowledgements}

Primarily, I would like to thank Dr. V'yacheslav Akkerman who has been outstanding as both a teacher as well as a research advisor. Without his patience and guidance, I would not have been able to finish my degree.

I would also like to thank Dr. Hayri Sezer, who introduced me to the EVA solver. His guidance and suggestions were vital in completing this thesis. I am also grateful to Jérôme Taveau, who supplied me with numerous experimental papers, as well as to Sinan Demir, who was my primary resource for numerous questions.

Finally, I would like to thank my friends and family for their unwavering support and encouragement. 


\section{Table of Contents}

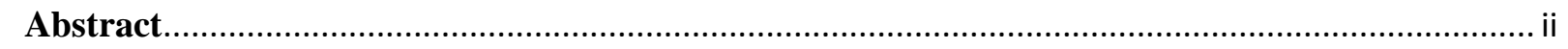

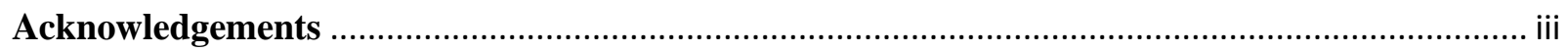

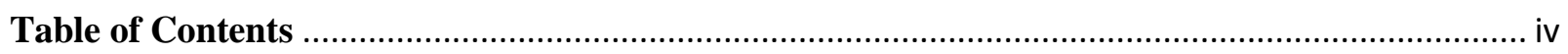

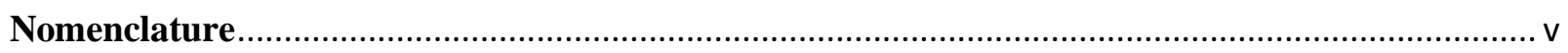

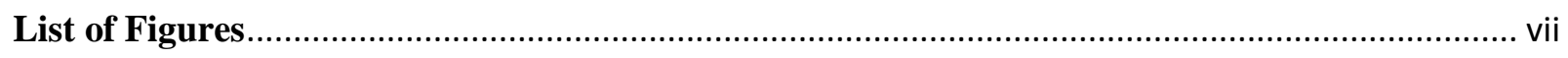

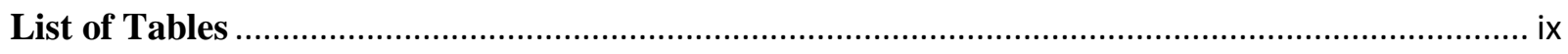

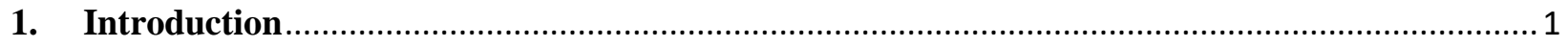

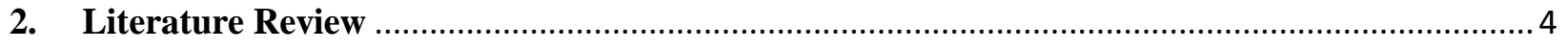

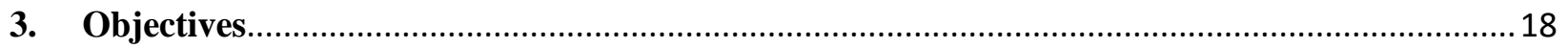

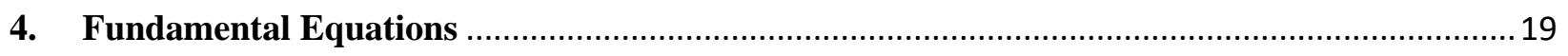

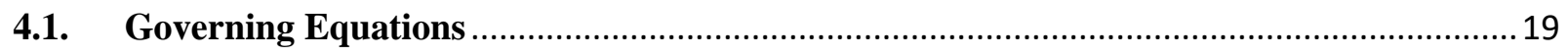

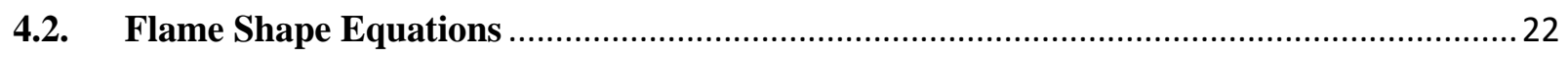

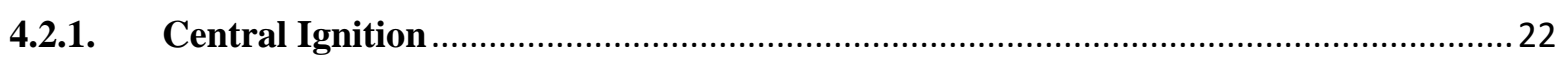

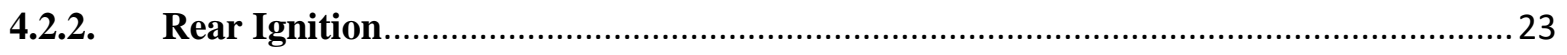

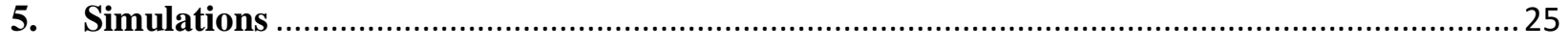

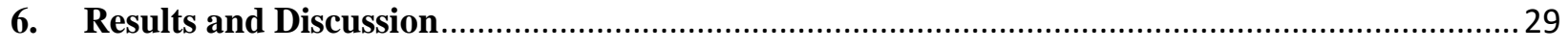

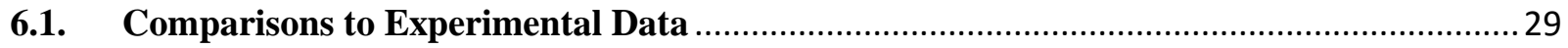

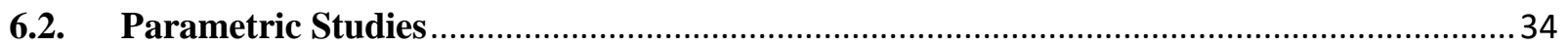

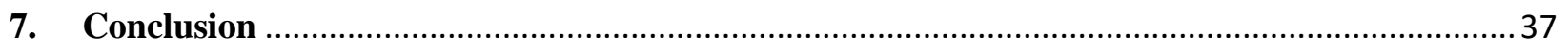

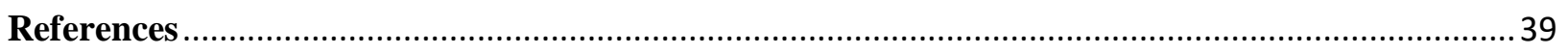




\section{Nomenclature}

\section{Latin Letters}

a geometric variable

A area

$\bar{A} \quad$ vent area ratio

b geometric variable

c geometric variable

$C_{d} \quad$ coefficient of discharge

$C_{V} \quad$ average specific heat at constant volume

e shape parameter, defined in text

$e \quad$ internal energy

E total energy

$\mathrm{h}$ shape parameter, defined in text

1 length

$l \quad$ mean size of large eddies

m mass

P pressure

$\bar{P} \quad$ pressure ratio

$\bar{P}_{c} \quad$ critical pressure ratio

$\mathrm{r} \quad$ radius

R gas constant of mixture

S burning velocity 


$\begin{array}{ll}\mathrm{t} & \text { time } \\ \mathrm{T} & \text { temperature } \\ \mathrm{u}^{\prime} & \text { rms turbulent velocity } \\ \mathrm{V} & \text { volume }\end{array}$

\section{Greek Letters}

$\alpha \quad$ flame speed variable defined in Eq. (2.15)

$\beta \quad$ flame speed variable defined in Eq. (2.16)

$\gamma \quad$ specific heat ratio

$\zeta \quad$ gas factor

$\eta^{3} \quad$ burnt gas volume

$\lambda \quad$ taylor microscale

$\rho \quad$ density

$\phi \quad$ equivalence ratio

\section{Subscripts}

$\begin{array}{ll}\text { b } & \text { burnt } \\ \text { c } & \text { center } \\ \text { i } & \text { initial } \\ \text { r } & \text { rear } \\ \text { u } & \text { unburnt } \\ \text { v } & \text { venting } \\ 0 & \text { reference }\end{array}$




\section{List of Figures}

Figure 1- Pressure evolution for two area ratios at four different vent pressures (Bradley \& Mitcheson, 1978a)

Figure 2- A pressure change for six vent pressures at different areas (Bradley \& Mitcheson, 1978a)

Figure 3- Variations of maximum pressure rise: experimental and computational (Bradley \& Mitcheson, 1978b)

Figure 4- Variations in maximum pressure: experimental and computational (Bradley \& Mitcheson, 1978b)

Figure 5-pressure change vs time in a sphere for experimental and computational data (Wilkin \& Mulpuru, 1982).

Figure 6- Pressure change vs time in a cylinder for experimental and computational data (Wilkin \& Mulpuru, 1982)

Figure 7-Flame propagation shapes varying with ignition location (Ugarte, et al., 2016) .13

Figure 8-Peak pressure comparison from (Ugarte, et al., 2016). Results include three flame velocity expressions: ST,1 (black), ST,2 (blue) and ST,3 (red) (Sezer, et al., 2016)

Figure 9- Overpressure evolutions for 14\% (blue), $16 \%$ (red) and 18\% (black) hydrogen for rear (solid) and central ignition (dashed) (Sezer, et al., 2016). 15

Figure 10- a) Flame velocity, b) vented mass and c) overpressure transients at $\phi=0.8,1.0,1.2$ for methane-air mixture in a cuboid (Ugarte, et al., 2016).

Figure 11-a) Flame velocity b) Vented mass c) Overpressure transients at $\phi=0.8,1.0,1.2$ for propane-air mixture in a cuboid (Ugarte, et al., 2016)

Figure 12- Steps in the development of the EVA .18 
Figure 13- Typical pressure spikes of a vented explosion (Cooper \& FairWeather, 1986).

Figure 14-Experimental setup replicated with the EVA solver (Bauwens, et al., 2008)

Figure 15- The geometry of the computational domain used by (Bauwens, et al., 2008)

Figure 16- Overpressure versus time for various venting pressures: the EVA solution and experimental data from (Bao, et al., 2016).

Figure 17- Overpressure versus time for $2.7 \mathrm{~m}^{2}$ vent with rear ignition 30

Figure 18- Overpressure versus time for $2.7 \mathrm{~m}^{2}$ vent with center ignition 31

Figure 19- Overpressure versus time for $5.4 \mathrm{~m}^{2}$ vent with rear ignition

Figure 20- Overpressure versus time for $5.4 \mathrm{~m}^{2}$ vent with center ignition .33

Figure 21- Parametric study of maximum overpressure, where the area is varied in the range of 0$12 \mathrm{~m}^{2}$ 35

Figure 22- Parametric study of maximum overpressure for equivalence ratio in the range of 0.7-1.2 


\section{List of Tables}

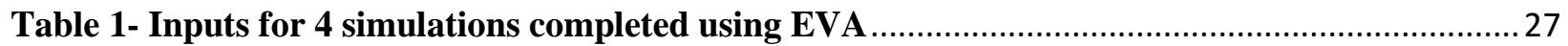

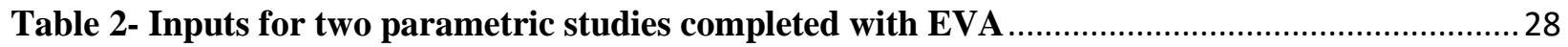

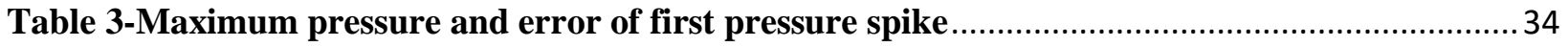




\section{Introduction}

In residential or industrial spaces, the possibility of accumulation of flammable gas and explosion constitutes a very realistic danger. When said explosion takes place, the damage is made by means of overpressure created by the expanding gasses. In an industrial environment, various mechanisms can lead to an accumulation of flammable gasses depending on the industry itself. In residential buildings, buildups of natural gas are a very common cause of these accidents. In May of 2015, construction crews were working within an apartment building in New York City when they struck a gas main. The building was filled with a gas, which was eventually ignited. The force of the explosion was enough to destroy the building as well as putting the neighboring structure on "the verge of collapsing". Fortunately, while 19 people were injured and four of them critically, nobody was killed (Fox News, 2015) .

When such explosions happen, the pressure increases until it can escape, which usually takes place through some kind of venting such as a blown out window or similar. Proper planning of these venting areas can reduce the potential for severe damage and loss of life greatly. For example, in nuclear reactors, extremely high temperatures during a runaway cause a reaction between water and zirconium in the fuel rods that splits the water. The resulting hydrogen buildup can ignite and damage the containment structures. This took place at Three Mile Island in the 1979 accident, as well as in all three nuclear reactors at the Fukushima power plant in 2011 (Biello, 2011). Accidental hydrogen explosion also constituted the key of the Chornobyl catastrophe in 1986. It is noted, in this respect, that the damage to the containment structures of the reactor, and therefore radiation leaks, could be reduced or avoided by means of proper venting of the combustion gasses.

Inspired by frequent mining disasters in the early 1800s, one of the first works on explosion safety was performed by Sir Humphry Davy. His solution was to prevent mining disasters by using specialized lamps that restricted an oxygen flow to a flame (Davy, 1815). Davy's special lantern did not have the desired effect, but it initiated the studies of explosion physics from the safety viewpoint. This investigation substantiated importance of explosion venting. Understanding the influence of the vents on the pressures inside the volume is vital for creating better guidelines. This may allow improvements in survivability and durability as well as lowering costs. 
In the past, guidelines to ensure a building had adequate venting were given exclusively by phenomenological models identified from experiments. One of the works of this kind was performed by Cubbage \& Marshall (1974). In this work potential explosions in industrial enclosures containing pressures slightly higher that atmospheric, such as kilns or furnaces, were considered. By conducting experiments in a small chamber of volume $0.14 \mathrm{~m}^{3}$, a relation between energy contained in a volume of gas and pressure rise is generated. This relation is assumed to be valid for similar energy densities without considering volume. This relation is then combined with the previous work (Cubbage \& Marshall, 1973) to estimate pressure reduction from venting. The resulting equations are accurate only for scenarios very similar to the experiment. Similar relations for different scenarios of vented explosions were completed in (Palmer, 1956) and (Straumann, 1965) using experimental data. While valuable for specific situations, these methods are too simplified to be entirely accurate and have significant room for improvement.

A common strategy to solve this problem, and others similar to it, is to use direct numerical simulation. This method is accurate and provides valuable insight to the interactions taking place within a system. This method however, is not suited for all applications. The problem of explosion venting in a volume contains many complex fluid interactions. Fully simulating these interactions is computationally expensive and the programs written to simulate them are complex. These programs are not only difficult to use, but can be impossible to modify for different situations. These difficulties draw attention to the need for a computationally inexpensive model that can accurately predict these processes, while being easy to use and modify. My thesis is one of the steps in this direction.

Once a flame is ignited, it expands outwardly because of two processes. First, a premixed flame front naturally propagates normally to itself. Second, there is a significant decrease in density between the unburnt and burnt matter. The new volume generated by these processes expands towards the walls of the vessel. Because the expansion is limited by the walls, and the combustion products have considerably less density than the fresh has, the new gas volume is generated and thereby pressure increases. While without venting a flame front will be sphericalin-mean, when a venting occurs the flame will move with the gas and get distorted towards the vent. The venting gasses relieve the overpressure within the vessel. The capability of a vent to do 
this depends on the vent shape, size, mass and density of the venting gas. The balance between this venting and the rate of burning, which depends on the type of fuel, the equivalence ratio, and the flame shape, determines how of large a pressure spike will occur within a volume.

By using applicable assumptions and simplifications, the three-dimensional (3D) problem can be reduced to a zero-dimensional one (with time as the only variable). Properly applying these assumptions greatly reduces the required computing power without significantly affecting accuracy. The objective of this thesis is to study the effects of vented deflagration using these zero-dimensional equations. This is performed by using the Explosive Vent Analyzer (EVA) developed by the joint team of West Virginia University (WVU) and Worcester Polytechnic Institute (WPI). The results from these studies are compared to experiments and computational fluid dynamics (CFD) simulations. Accuracy of this model to predict the experiment will be judged against the accuracy of the CFD model. 


\section{Literature Review}

Bradley \& Mitcheson (1978a), who developed a model of explosion relief and compared the model to various experimental results, created the foundation for the present thesis. Based on these results, suggestions were made for guidelines of venting area requirements in buildings. The study was performed for a well-insulated spherical enclosure ignited at the center. The interior and exterior initial pressures are $1.0 \mathrm{~atm}$ and gasses are assumed to be premixed and uniform ideal gasses.

This work relied on various simplifying assumptions regarding the venting process. The first was that venting begins instantaneously and completely as soon as the vent opening pressure is reached. Second, the gas is then vented evenly across the surface of the sphere, allowing a constant flame shape to be maintained. This allows the model to be based on concentric spheres, simplifying the equations for flame area and venting. The burning rate is based on the flame shape and velocity, namely

$$
\begin{gathered}
\frac{d m_{b}}{d t}=4 \pi r_{b}^{2} \rho_{u} S \\
\frac{d m_{u}}{d t}=-4 \pi r_{b}^{2} \rho_{u} S
\end{gathered}
$$

Here Eqs. (2.1) and (2.2) describe the evolution of the burnt and unburnt matter, respectively. In order to calculate the amount of gas vented through the opening, orifice equations are used. Namely, the mass flow rate of venting at specific pressure, density, and temperature is computed. The equations rely on a discharge coefficient, which relates actual and theoretical flow rates for different geometries. Given by the British Standards Institution (1964), these equations will be presented in Sec. 3. There are two separate versions of the equations, namely, sonic and subsonic venting. The difference between the two regimes is given by the critical pressure ratio $\bar{P}_{c}$.

As a spherical flame expands, the flame surface area increases, which leads to an increase in the flame velocity through the growth of heat transfer to the surrounding unburnt gas (Travnikov, et al., 2000). This takes place in the geometry studied by Bradley \& Mitcheson (1978a). When the flame reaches the wall of the sphere, the surface area is maximal and therefore the flame speed and overpressure are also at their largest point. This maximum pressure has been used to estimate the minimum required vent area (Bradley \& Mitcheson, 1978a). Then 
the difference between the volumetric venting rate and the increase in the burnt gas volume due to pressure change reads

$$
S_{v} 4 \pi R^{2}\left(\frac{\rho_{u v}}{\rho_{b v}}-1\right)
$$

This can then be used to calculate the vent area for sonic and subsonic flows respectively,

$$
\overline{\bar{S}}>\left(\frac{\gamma+1}{2}\right)^{\frac{1+\gamma}{2(\gamma-1)}}, \quad \text { (2.4a) } \quad \frac{\bar{A}}{\bar{S}}>\left\{\frac{2}{\gamma-1}\left(\frac{P_{a}}{P_{v}}\right)^{\frac{2}{\gamma}}\left[1-\left(\frac{P_{a}}{P_{v}}\right)^{\frac{\gamma-1}{\gamma}}\right]\right\}^{-0.5} .
$$

where $\bar{A}$ and $\bar{S}$ are defined as

$$
\bar{A}=C_{d} \frac{A_{v}}{A_{s}},
$$

$$
\bar{S}=\frac{S_{v}}{a_{v}}\left(\frac{\rho_{u v}}{\rho_{b v}}-1\right) .
$$

By introducing terms representing the values of $\bar{S}$ and $a_{v}$ at their initial conditions, $\bar{S}_{0}$ and $a_{v 0}$, the simplified versions of Eqs. (2.4a) and (2.4b) can be created. With a gas factor $\zeta_{i}$, which is different for burnt and unburnt gas, namely

$$
\zeta_{u}=\frac{S_{v}}{S_{0}} \frac{\left(\frac{\rho_{u v}}{\rho_{b v}}-1\right)}{\left(\frac{\rho_{u 0}}{\rho_{b 0}}-1\right)}\left(\frac{P_{a}}{P_{v}}\right)^{\frac{\gamma_{u}-1}{2 \gamma_{u}}}, \quad(2.6 a) \quad \zeta_{b}=\zeta_{u}\left(\frac{\gamma_{u}}{\gamma_{b}} \frac{\rho_{b v}}{\rho_{u v}}\right)^{0.5}
$$

This finally yields the equations for the venting relationship (Bradley \& Mitcheson, 1978),

$$
\begin{gathered}
\overline{\overline{S_{0}}}>\left(\left(\frac{\gamma_{i}+1}{2}\right)^{\frac{1+\gamma_{i}}{2\left(\gamma_{i}-1\right)}}\right) * \zeta_{i}, \\
\frac{\bar{A}}{\overline{S_{0}}}>\left(\left\{\frac{2}{\gamma_{i}-1}\left(\frac{P_{a}}{P_{v}}\right)^{\frac{2}{\gamma}}\left[1-\left(\frac{P_{a}}{P_{v}}\right)^{\frac{\gamma_{i}-1}{\gamma_{i}}}\right]\right\}^{-0.5}\right) * \zeta_{i} .
\end{gathered}
$$

The Bradly-Mitcheson computational method utilizes the conservation of mass and volume. The solution relies strongly on the burning velocity and a relationship for the isentropic variation of stoichiometric methane-air laminar burning velocity, which is (Bradley \& Mitcheson, 1976)

$$
S=10+0.000371 T^{2}-0.0052 T^{1.5} \log _{10} P \mathrm{~cm} / \mathrm{s}
$$


The specific heat ratios were interpolated from the tables of (Mayhew \& Rogers, 1971) and (Haywood, 1968).

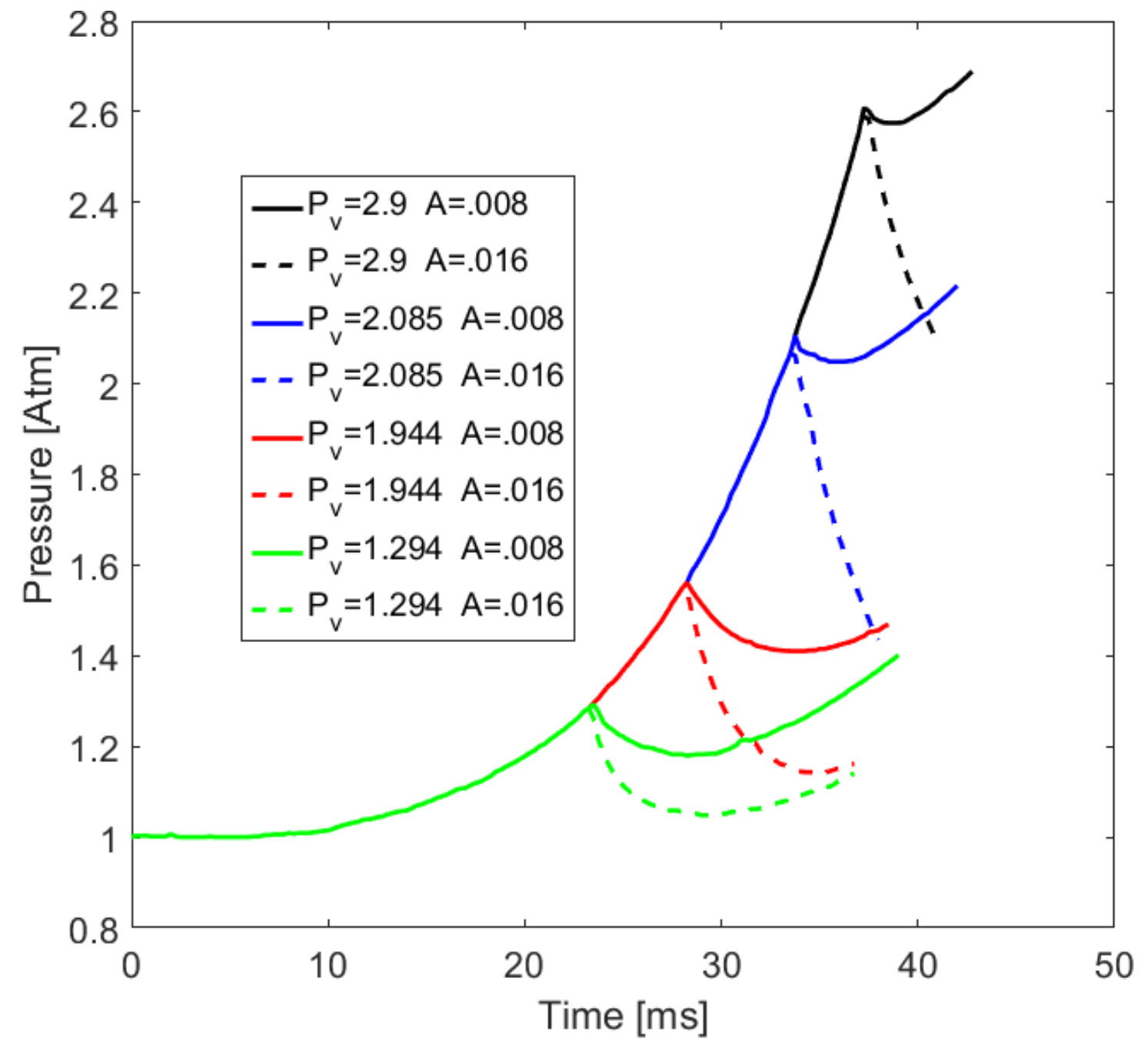

Figure 1- Pressure evolution for two area ratios at four different vent pressures (Bradley \& Mitcheson, 1978a)

Eight solutions at an initial pressure of $1 \mathrm{~atm}$, a temperature of $298 \mathrm{~K}$ and a vessel radius of $0.1 \mathrm{~m}$ were used. Four vent opening pressures were considered, each with two values of $\bar{A}$. Solutions for these eight geometries are shown in Fig. 1.

Qualitatively, the results show that the first pressure peak occurs at the designated vent opening pressure. It also shows that depending on the size of the vent, there may or may not be a second peak, as the accelerating flame front creates pressure which is too large for the vent to relieve. 


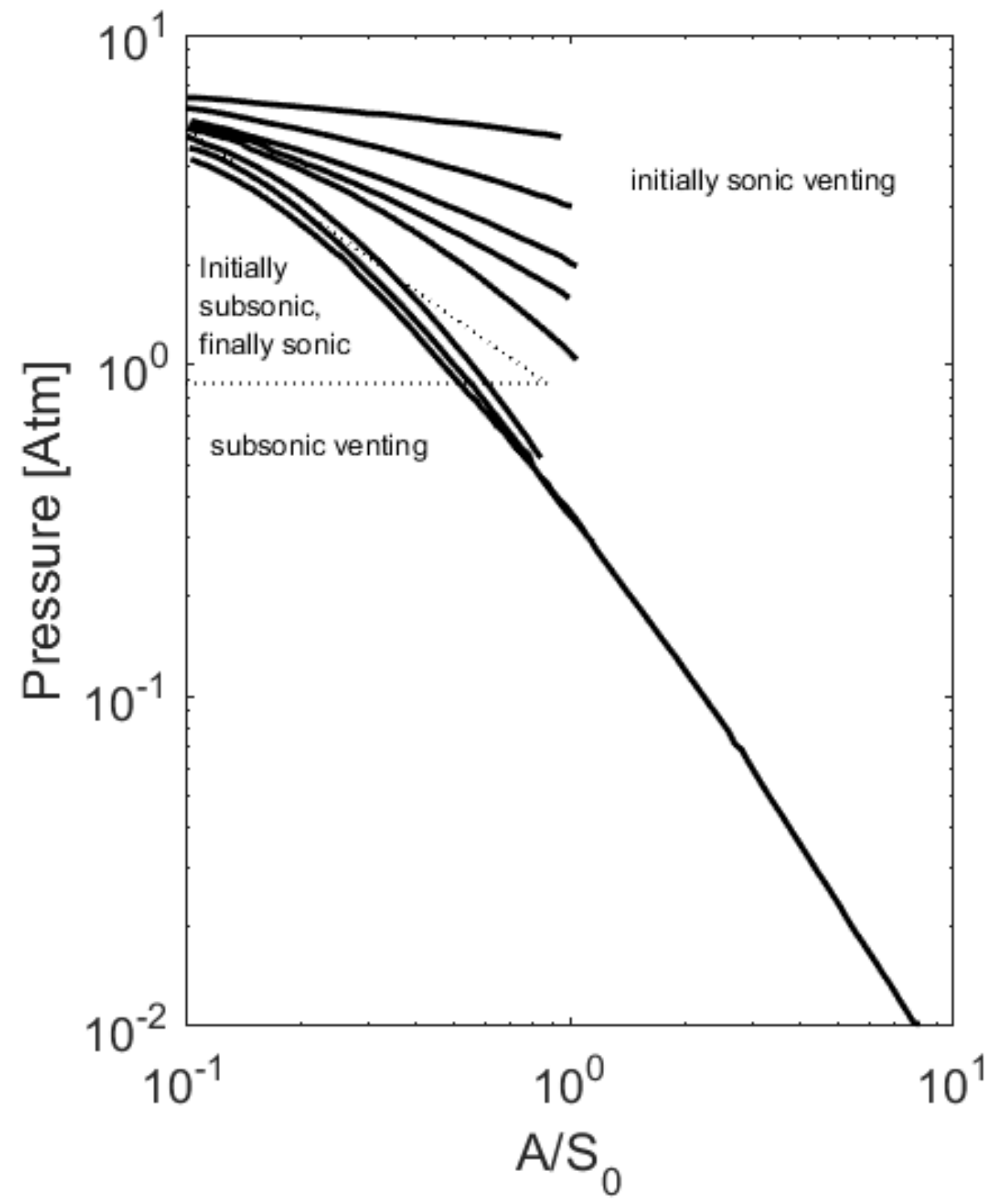

Figure 2- A pressure change for six vent pressures at different areas (Bradley \& Mitcheson, 1978a)

A more comprehensive illustration for the effects of vent pressures in the range 1-6 atm is shown in Fig. 2, where a vent pressure of 1 atm implies an open vent. The simulation shows the three types of venting, namely: (i) fully subsonic, (ii) transitional from sonic to subsonic, and (iii) transitional from sonic to subsonic.

In the results of (Bradley \& Mitcheson, 1978b), for an initially uncovered vent, Fig. 3, the dashed line represents the simulations and the solid lines represent various experiments. It is seen that the simulation and experimental results are in fair agreement. 


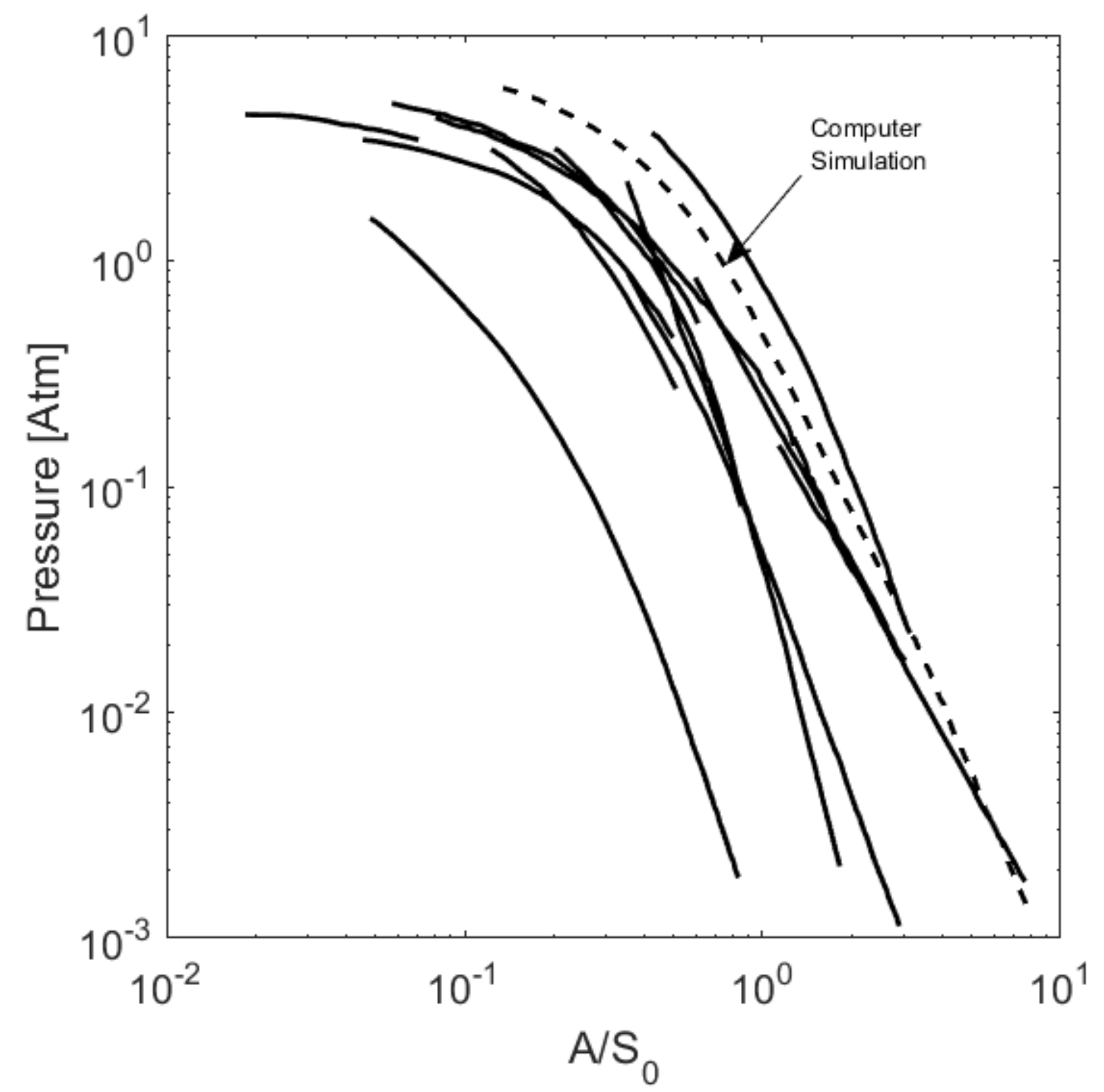

Figure 3- Variations of maximum pressure rise: experimental and computational (Bradley \& Mitcheson, 1978b)

For initially covered vents, Bradley \& Mitcheson, (1978b) have presented the data from 34 different experiments, several of which are depicted in Fig. 4. It is seen that the model underestimates pressures for most of the experiments, and it appears much less accurate than the model for initially opened vents. Bradley \& Mitcheson (1978b) attributed this discrepancy to the increase in the burning velocity and turbulence, which greatly increases the pressure. It was theorized that this is caused by the rapid opening of the vent, which generates a pressure wave that increases unsteadiness. Reductions in peak pressures have been observed by replacing a bursting vent cover with a smooth opening explosion door. 


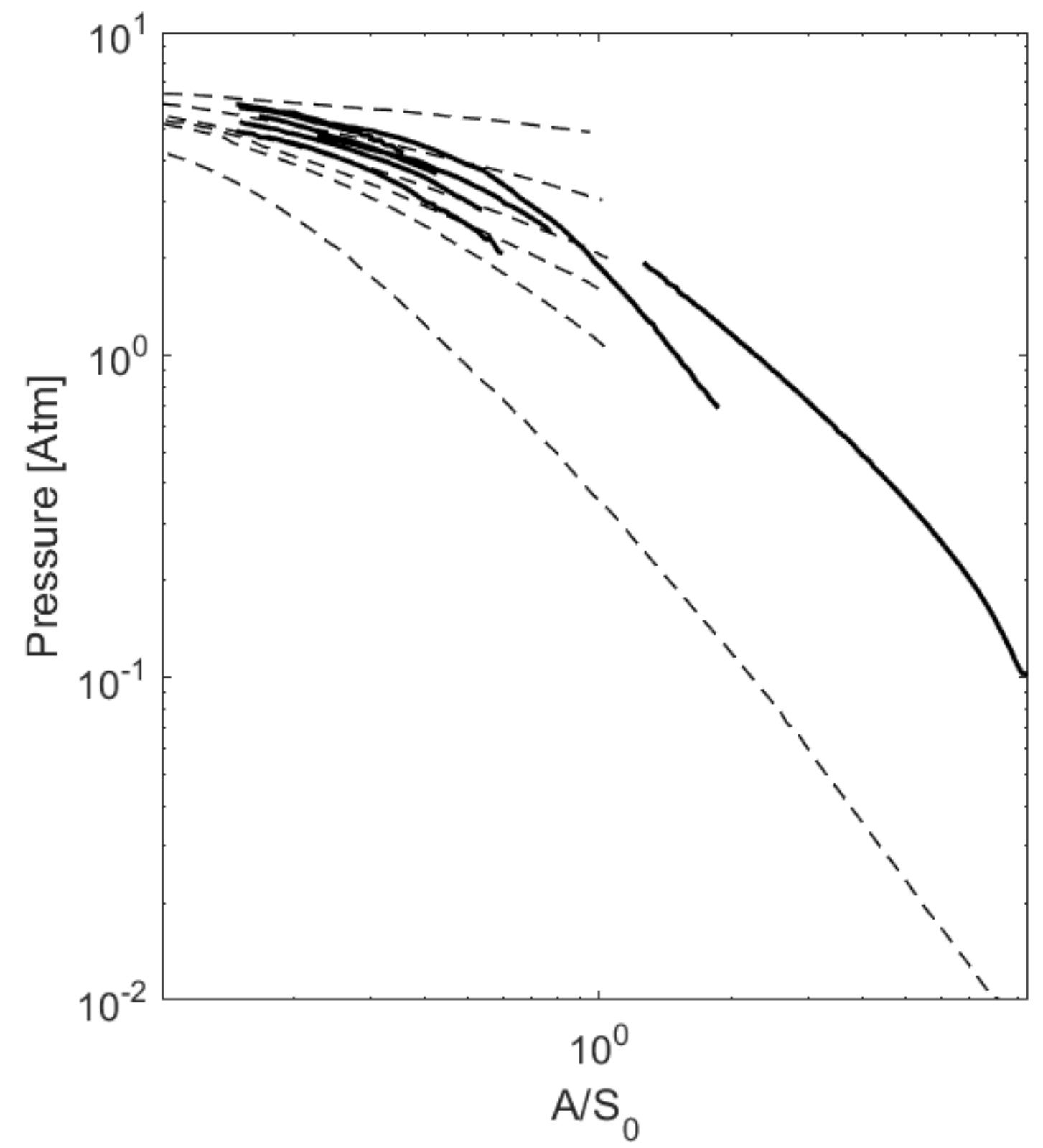

Figure 4- Variations in maximum pressure: experimental and computational (Bradley \& Mitcheson, 1978b)

Several other factors also contribute to the peak pressures according to Bradley \& Mitcheson (1978b). First, if the ignition source is close to the vent, then the burnt gas is vented sooner allowing a greater reduction. The opposite is also true: an ignition source far from the vent will allow a greater volume of burnt gas, and therefore surface area of flame, to develop before venting begins. This effect is discussed further later in this section. Second, turbulence and, therefore, the flame velocity are greatly increased by obstructions in the volume. Bradley \& 
Mitcheson (1978b) suggested that the risk of flame acceleration due to obstacles may be reduced by using distributed vents as opposed to one large vent. Third, the design of the vent itself has a large effect on the pressure. The coefficient of discharge is set at 0.6 for this work, however, using suitably designed nozzles may allow this to increase significantly.

While the results from these models are reasonable, there is still significant room for improvement of accuracy. However, these results as well as the guidelines of (Bradley \& Mitcheson, 1978b) generated from them, are improvements over the phenomenological models, which were used previously to predict pressure spikes.

Drawing partially from (Bradley \& Mitcheson, 1978a), a model for vented deflagration of hydrogen has been developed by (Wilkin \& Mulpuru, 1982). This model employed a zerodimensional simplification of the system and greatly reduces the computational power as compared to (Bradley \& Mitcheson, 1978a). The model (Wilkin \& Mulpuru, 1982) also allows ignition to occur at different locations, thus causing the vented gas to be either burnt or unburnt.

In order to simplify to the zero-dimensional equations, Wilkin \& Mulpuru (1982) made several assumptions. First, the gasses are assumed to be well-mixed, ideal, and ignited at a single point in the volume. Second, the flame is assumed to be infinitely-thin and globally-spherical, propagating, uniformly, outwardly from the ignition point. Third, the flame is slow enough to pressure in the volume being uniform, and all expansions and compressions are isentropic. Finally, all the properties of the burnt and unburnt matter are spatially uniform.

To derive the governing equations, Wilkin \& Mulpuru (1982) used mass balance and energy balance equations

$$
\begin{gathered}
\frac{d}{d t}\left(\frac{m_{u}}{m_{i}}\right)+\frac{d}{d t}\left(\frac{m_{b}}{m_{i}}\right)+\frac{d}{d t}\left(\frac{m_{v}}{m_{i}}\right)=0, \\
\frac{d}{d t}\left(\frac{m_{u}}{m_{i}} E_{u}\right)+\frac{d}{d t}\left(\frac{m_{b}}{m_{i}} E_{b}\right)+E_{u} \frac{d}{d t}\left(\frac{m_{v}}{m_{i}}\right)=0 .
\end{gathered}
$$

It is noted that the resulting equations are the fundamental governing equations used in the model for explosive venting in this paper; their detailed derivations are presented in Section 3.

This method of the problem solution relies on the hydrogen burning velocity, given by

$$
s_{l\left(\frac{m}{s}\right)}=\left[A_{1}+A_{2}\left(0.42-x_{H_{2}}\right)+A_{3}\left(0042-x_{H_{2}}\right)^{2}\right]-T_{u}^{\left[A_{4}+A_{5}\left(0.42-x_{H_{2}}\right)\right]} \exp \left(A_{6} x_{H_{2} O}\right)
$$




$$
\frac{S_{l}}{S_{l 0}}=\left(\frac{P}{P_{0}}\right)^{x}
$$

where the constants $A_{1}$ through $A_{6}$ are referenced from (Liu \& MacFarlane, 1981).

Because turbulence greatly increases the burning rate as compared to laminar burning, its effects should be accounted. This is done by using a correlation between the ratio of the turbulent to laminar flame speeds and the turbulent Reynolds number $\left(R e_{\lambda}\right)$. The latter is calculated using the following relation for isotropic turbulence between Taylor microscale $(\lambda)$ and the mean size of large eddies $(l)$ referenced from (Dryden, 1943).

$$
\frac{\lambda^{2}}{l}=48.64 \frac{v}{u^{\prime}}
$$

Wilkin \& Mulpuru (1982) used a fourth-order Runge-Kutta explicit method to solve the derived equations.

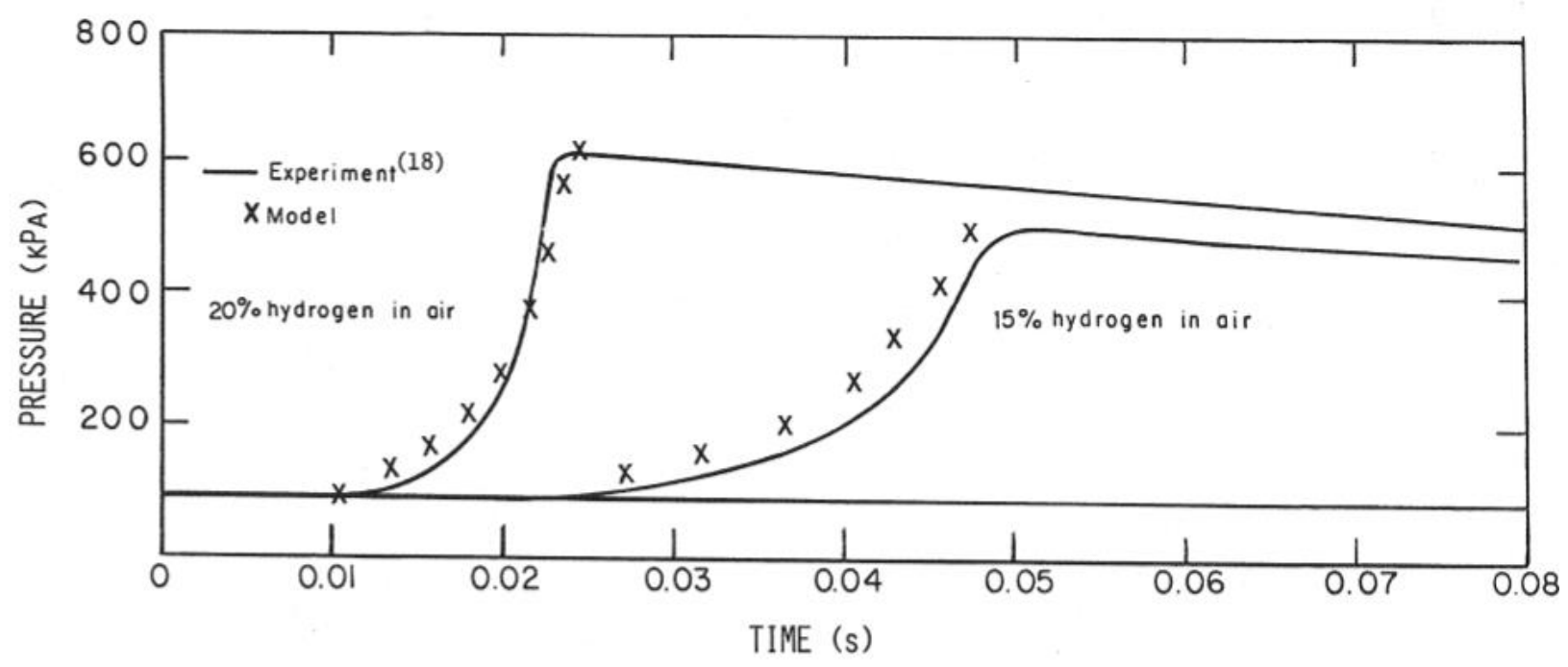

Figure 5-pressure change vs time in a sphere for experimental and computational data (Wilkin \& Mulpuru, 1982)

The results agree with experiments for the sphere geometry as shown in Fig. 5. Figure 6 compares the computational results of (Wilkin \& Mulpuru, 1982), for the cylindrical geometry, to the experimental data (Cousins \& Cotton, 1951). In fact, more complex geometry of the cylinder contains more complex physical interactions, such as turbulence and distortion of the flame shape, that (Wilkin \& Mulpuru, 1982) does not consider. Therefore, while the numerical results agree qualitatively with the experimental ones, the experimental pressures are noticeably higher. Wilkin \& Mulpuru (1982) concluded that more accurate terms for the flame front surface area and burning velocity would greatly improve the results. 


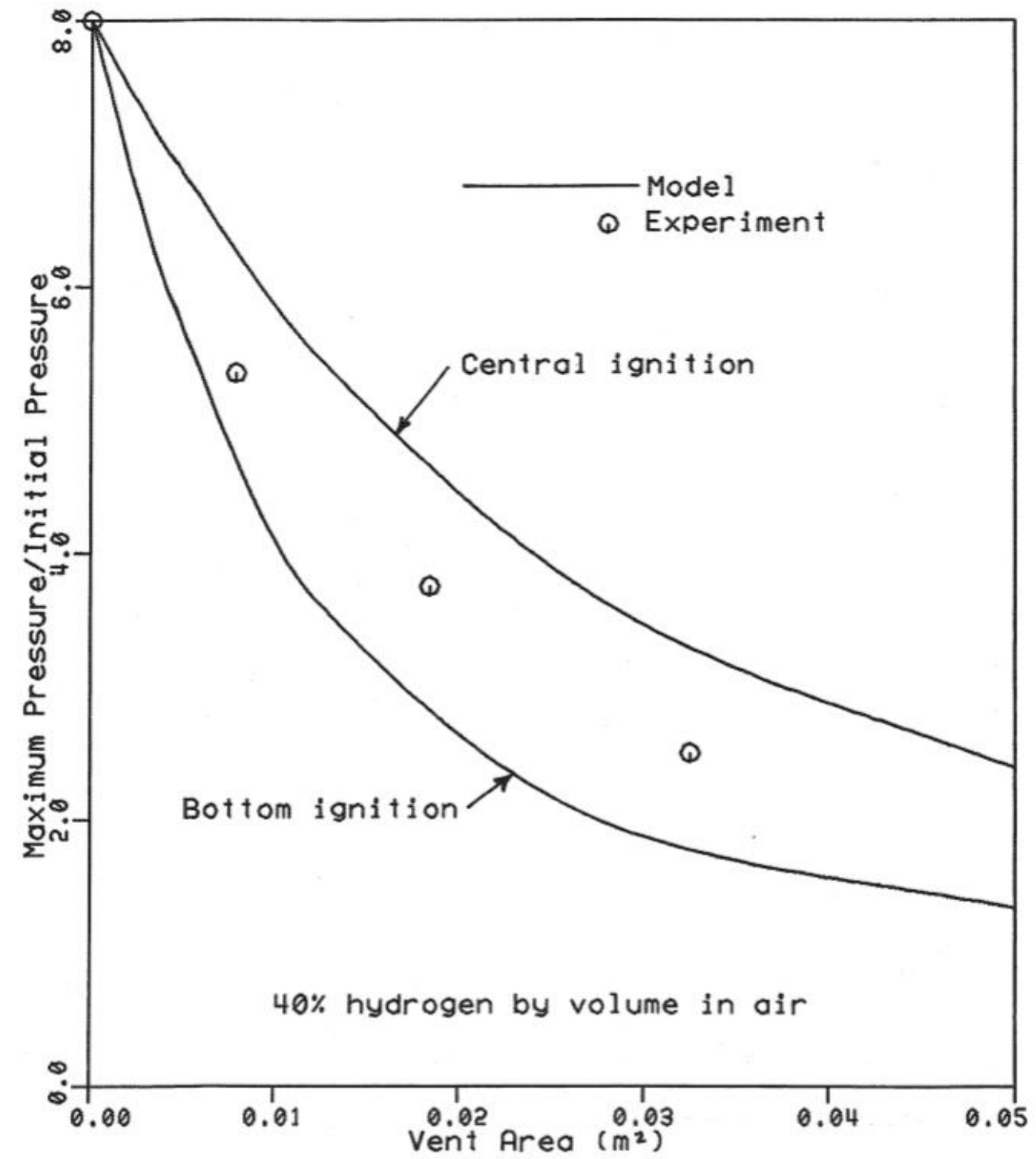

Figure 6- Pressure change vs time in a cylinder for experimental and computational data (Wilkin \& Mulpuru, 1982)

Ugarte et al. (2016) have recently developed a model for explosion venting that is utilized in the present thesis. The work develops the EVA and builds on (Wilkin \& Mulpuru, 1982) with several significant modifications. While the three governing equations are generally the same as in (Wilkin \& Mulpuru, 1982), and the fourth-order Runge-Kutta method is still utilized, the major changes come with the auxiliary relations. The equations for flame propagation velocity and flame shape are all improved. There is also an additional consideration for the role of an external explosion in the venting process. 

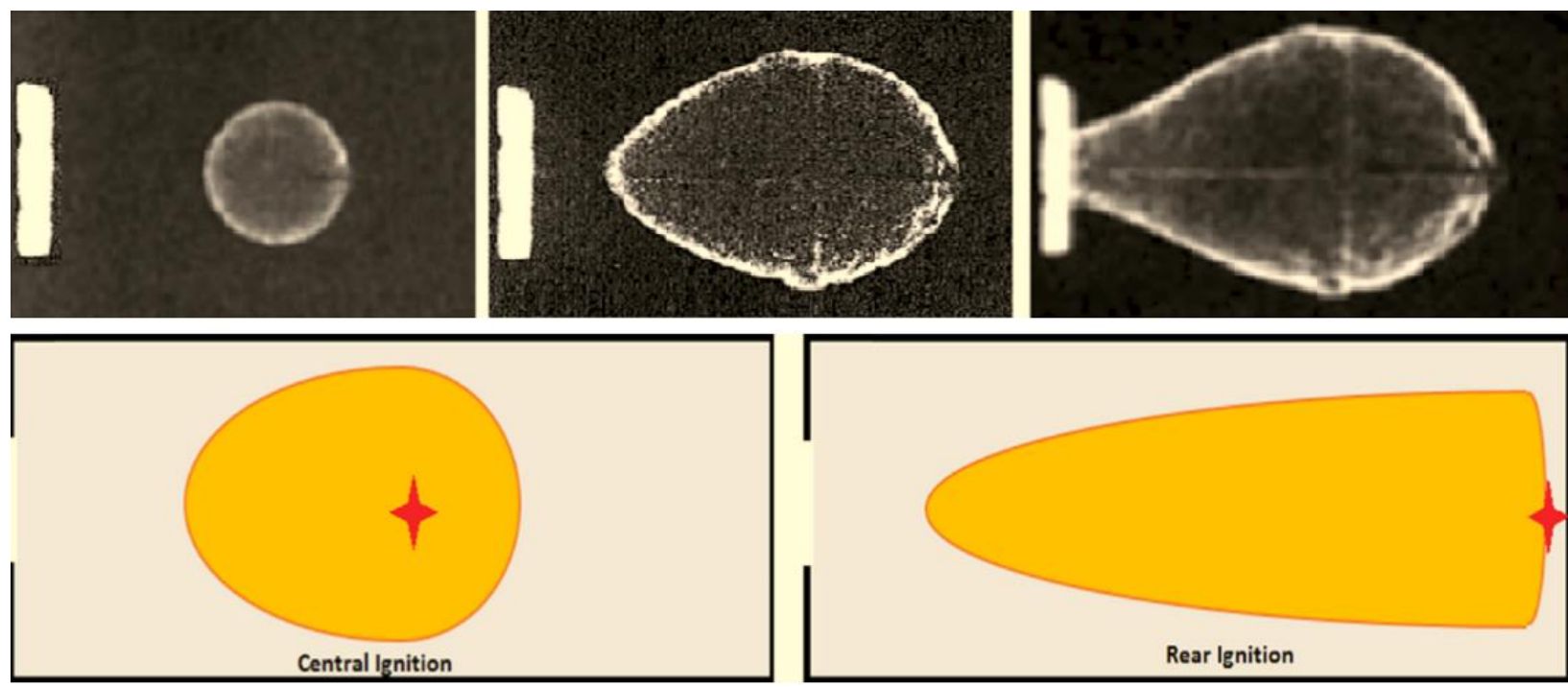

Figure 7-Flame propagation shapes varying with ignition location (Ugarte, et al., 2016)

Figure 7 shows the internal flame propagation at various phases of a vented explosion (Cooper \& FairWeather, 1986). It is seen that shortly after ignition, an initially spherical flame front starts elongating towards the vent, where pressure effects from the wall are not present. Accurately representing this flame shape is vital, since the flame surface area is directly related to the flame speed, as discussed earlier. The flame shape can be modeled, with reasonable accuracy, as a half-circle facing the closed end, and a half-ellipsoid moving towards the vent. (Ugarte, et al., 2016) also considers ignition taking place on the center of the rear wall opposite of the vent. The flame from this rear ignition would take the shape of a half-ellipsoid expanding towards the vent. Once the flame reaches the vent, a term is added to account for flame front exiting the enclosure, which is also in the shape of an ellipsoid. These approximations are illustrated in Fig. 7 and equations for this geometry are given in Sec. 4.2.

The flame propagation velocity is calculated using three different methods. First, it is obtained from the general equation given by (Liu \& MacFarlane, 1981). The second method employs an additional constant based on the works (Heimel, 1957) and (Drell \& Belles, 1958). The third estimation for the flame speed is found by differentiating the equation for a globally spherical flame front corrugated by the Darrieus-Landau flame instability.

A significant consideration by (Ugarte, et al., 2016) is the effect of external pressure changes due to external explosions. When unburnt gas is vented, it is eventually ignited causing a pressure spike and reduction in venting. This is modeled by replacing the exit pressure with a term that increases when the flame reaches the vent. The external cloud of gas that is ignited is modeled as an ellipsoid, for which a term for pressure spike is referenced from (Strehlow, 1979). 
The shape of the cloud is estimated as $\mathrm{D} / \mathrm{L}=2$. The length is estimated by the amount of unburnt gas vented prior to ignition.

This model was employed to calculate the overpressures for hydrogen at different concentrations and different geometries, using the three different methods for finding flame speed. Figure 8 shows a comparison between these calculations and matching experiments, completed by (Bauwens, et al., 2012). The maximum difference between the model and experiments was around 30\%. The error is larger for small vent sizes when the flame shape is more distorted from that used in the model.

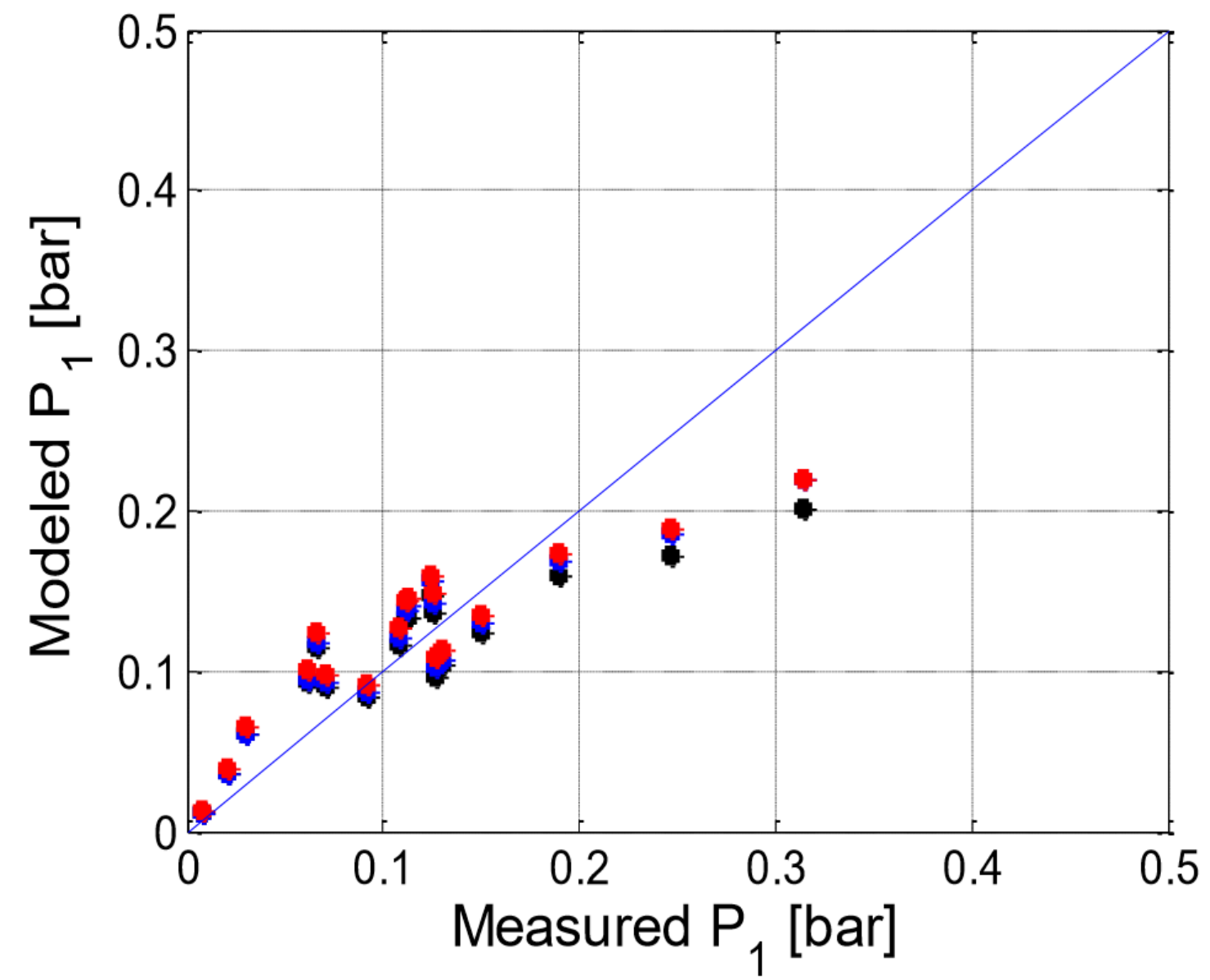

Figure 8-Peak pressure comparison from (Ugarte, et al., 2016). Results include three flame velocity expressions: ST,1 (black), ST,2 (blue) and ST,3 (red) (Sezer, et al., 2016)

The EVA solver was subsequently used to calculate the results for hydrogen at three different concentrations, for both central and rear ignitions. This is shown in Fig. 9. It is found that rear ignition creates larger overpressures compared to center ignition. This is because the flame had a larger surface area before burnt gas starts venting, as well as because a larger 
external explosion due to more unburnt gas being vented. As expected, it is found that peak pressures are greater for smaller vent sizes. The results also show that cylinders have higher peak pressures than cuboids.

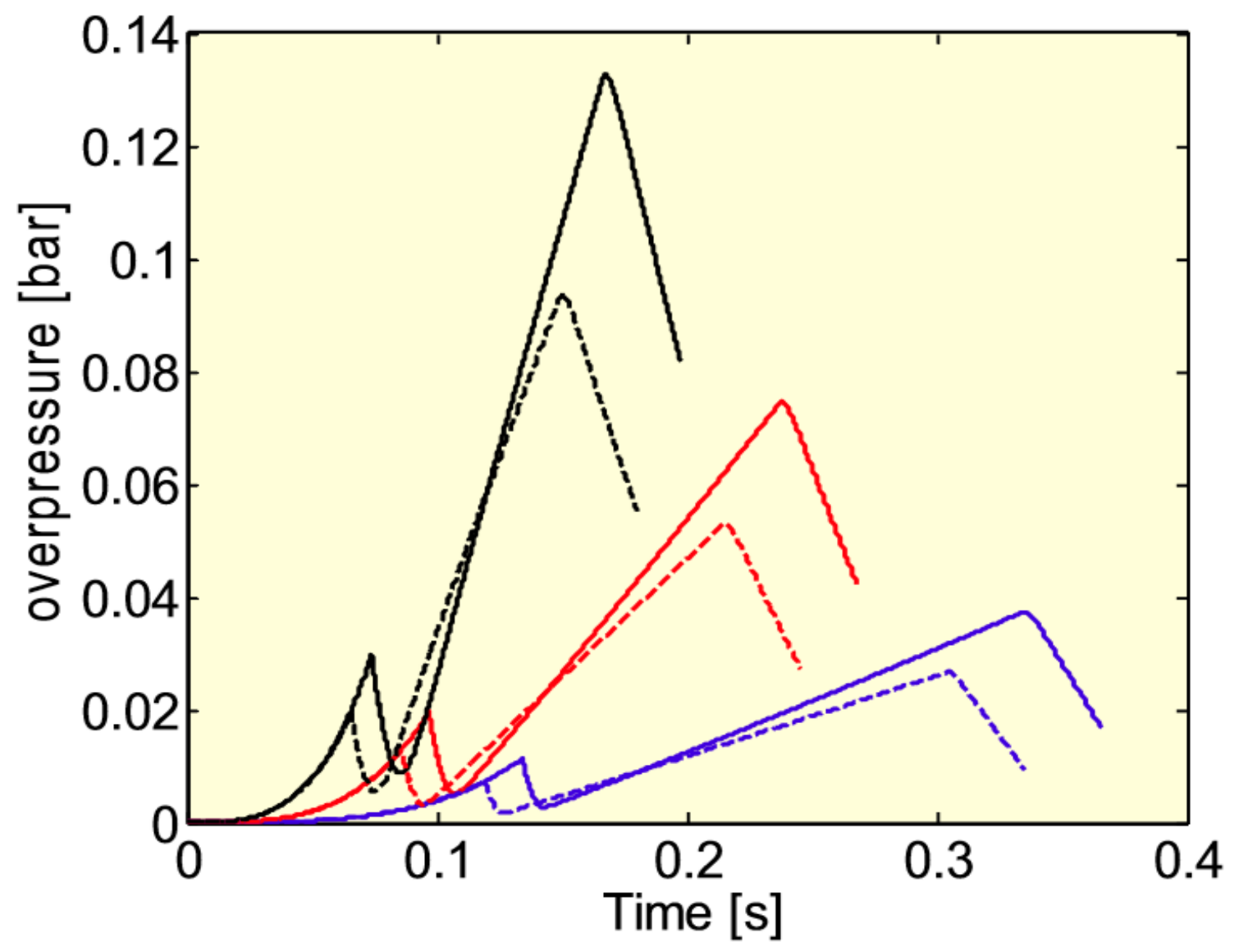

Figure 9- Overpressure evolutions for $14 \%$ (blue), $16 \%$ (red) and $18 \%$ (black) hydrogen for rear (solid) and central ignition (dashed) (Sezer, et al., 2016)

The analysis of Ugarte et al. (2016), for hydrogen explosions, has been subsequently extended to methane and propane (Sezer, et al., 2016). The overpressure during an explosion is directly related to the flame velocity, as noted previously in this thesis. Therefore, a model for methane and propane would require accurate expressions for the flame velocity. This is calculated using expressions from (Akram, et al., 2013) and (Metghalchi \& Keck, 1980). The laminar burning velocity is given by

The variables $\alpha$ and $\beta$ are

$$
S_{L}=S_{L, 0}\left(\frac{T_{u}}{T_{u, 0}}\right)^{\alpha}\left(\frac{P_{u}}{P_{u, 0}}\right)^{\beta} .
$$

$$
\alpha=1.42+1.98(\phi-1),
$$




$$
\beta=-0.314+608(\phi-1) .
$$

The initial flame speed, $S_{L, 0}$, for methane is calculated as (Stone, et al., 1998)

$$
S_{L, 0}=37.6+15.1(\phi-1)-221(\phi-1)^{2}-458(\phi-1)^{3}-358(\phi-1)^{4},
$$

while that for propane is given by (Metghalchi \& Keck, 1980)

$$
S_{L, 0}=38.31+24.84(\phi-1)-153(\phi-1)^{2} .
$$
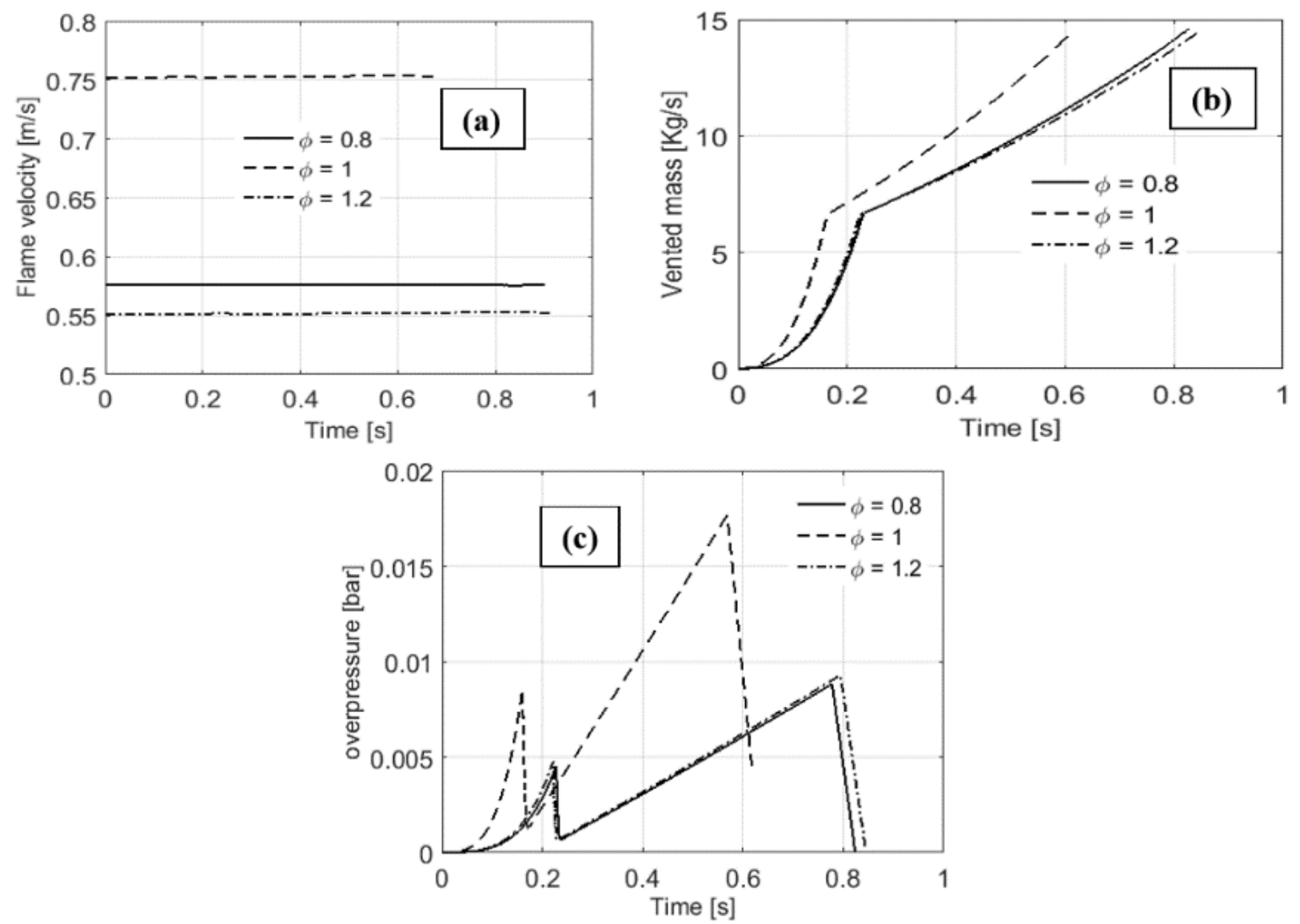

Figure 10- a) Flame velocity, b) vented mass and c) overpressure transients at $\phi=0.8,1.0,1.2$ for methane-air mixture in a cuboid (Ugarte, et al., 2016)

Another significant modification by (Sezer, et al., 2016) is the addition of the NASACAE computer code to calculate the properties of the methane-air and propane-air mixtures (Gordon \& McBride, 1996). The results of (Sezer, et al., 2016) show that there are only minor deviations between the flame velocities for both these gases. The results for methane are shown in Fig. 10. These results are very similar to that for propane, shown in Fig. 11. The maximum velocity is at an equivalence ratio of 1.0 for methane and 1.2 for propane. Moreover, the shape of the curve for vented matter and overpressure are similar for different equivalence ratios. There 
are large variations in the actual values, however, because of the increased flame speed. A double pressure spike is observed, similar to that found in (Ugarte, et al., 2016) for hydrogen combustion in air.
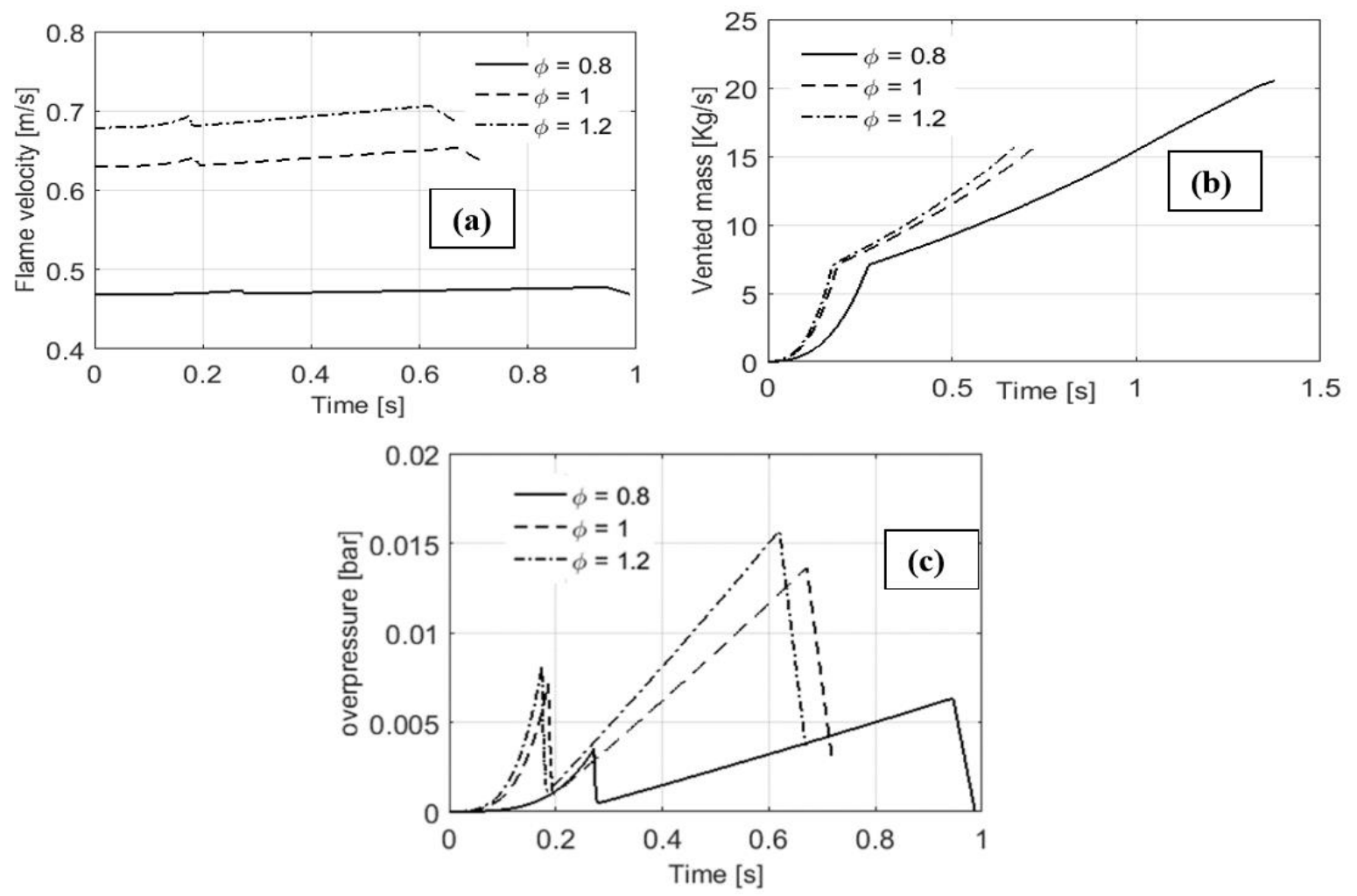

Figure 11-a) Flame velocity b) Vented mass c) Overpressure transients at $\phi=0.8,1.0,1.2$ for propane-air mixture in a cuboid (Ugarte, et al., 2016) 


\section{Objectives}

Figure 12 below shows the steps in the development of the Explosive Vent Analyzer (EVA), as discussed in the previous sections. This is the state-of-the art so far, and shown in green are the objectives of this thesis. First, in order to make the solver applicable to more situations, a consideration for venting pressure is added. The results from this addition are compared to the experimental data of (Bao, et al., 2016). Second, the results from the solver will be generated for geometries associated with experiments and CFD simulations (Bauwens, et al., 2012). The ability of the EVA to predict the experimental data will be compared to that of the CFD simulations. Finally, after the accuracy of EVA is determined, parametric studies will be carried out to determine the effect of vent size and equivalence ratio on the maximum overpressure.

\begin{tabular}{|c|c|c|c|}
\hline $\begin{array}{l}\text { Wilkin \& Mulpuru } \\
\text { (1982) }\end{array}$ & $\begin{array}{l}\text { Ugarte et al. } \\
\text { (2016) }\end{array}$ & $\begin{array}{l}\text { Sezer et al. } \\
\text { (2016) }\end{array}$ & $\begin{array}{c}\text { Kronz } \\
(2016)\end{array}$ \\
\hline $\begin{array}{l}\text { Derived } \\
\text { fundamental } \\
\text { equations used } \\
\text { in EVA } \\
\text { - Simulated } \\
\text { spheres and } \\
\text { cylinders }\end{array}$ & $\begin{array}{l}\text { - } \begin{array}{l}\text { Originated } \\
\text { the EVA } \\
\text { program }\end{array} \\
\text { - Included } \\
\text { equations for } \\
\text { Cuboid } \\
\text { enclosures }\end{array}$ & $\begin{array}{l}\text { - } \begin{array}{l}\text { Added } \\
\text { equations for } \\
\text { methane and } \\
\text { Propane }\end{array} \\
\text { - Added NASA- } \\
\text { CAE code }\end{array}$ & $\begin{array}{l}\text { - Added } \\
\text { parameter for } \\
\text { venting } \\
\text { pressure } \\
\text { - Compare to } \\
\text { CFD and } \\
\text { experiments } \\
\text { - Parametric } \\
\text { Studies }\end{array}$ \\
\hline
\end{tabular}

Figure 12- Steps in the development of the EVA 


\section{Fundamental Equations}

\subsection{Governing Equations}

Here the basic equations of the model are presented, beginning with a simple mass balance between unburnt, burnt, and vented mass. An energy term can be added for an energy balance equation:

$$
\begin{gathered}
\frac{d}{d t}\left(\frac{m_{u}}{m_{i}}\right)+\frac{d}{d t}\left(\frac{m_{b}}{m_{i}}\right)+\frac{d}{d t}\left(\frac{m_{v}}{m_{i}}\right)=0, \\
\frac{d}{d t}\left(\frac{m_{u}}{m_{i}} E_{u}\right)+\frac{d}{d t}\left(\frac{m_{b}}{m_{i}} E_{b}\right)+E_{u} \frac{d}{d t}\left(\frac{m_{v}}{m_{i}}\right)=0 .
\end{gathered}
$$

Using the isentropic relation $P / \rho^{\gamma u}=c$ and separating the mass into density and volume

$$
\begin{gathered}
\frac{m_{u}}{m_{i}}=\frac{\left(P_{u} C\right)^{\frac{1}{\gamma_{u}}}}{\left(P_{i} C\right)^{\frac{1}{\gamma_{u}}}} * \frac{V_{u}}{V_{i}}, \\
\frac{m_{u}}{m_{i}}=\frac{\left(P_{u}\right)^{\frac{1}{\gamma_{u}}}}{\left(P_{i}\right)^{\frac{1}{\gamma_{u}}}}\left(1-\eta^{3}\right), \\
\frac{m_{u}}{m_{i}}=\bar{P}^{\frac{1}{\gamma_{u}}}\left(1-\eta^{3}\right) .
\end{gathered}
$$

The orifice equations, discussed in Sec. 2, take two forms: one for a sonic flow and one for a subsonic flow. Specifically, the critical pressure ratio that determines to which regime the process falls into reads (Bradley \& Mitcheson, 1978a)

$$
\bar{P}_{c}=\left(\frac{2}{\gamma+1}\right)^{\frac{\gamma}{(\gamma-1)}} .
$$

For $P_{a} / P \leq 1 / \bar{P}_{c}$, when flow is sonic, the orifice equation is

$$
\frac{d}{d t}\left(\frac{m_{v}}{m_{i}}\right)=C_{d} \frac{A_{V} \rho}{m_{i}}\left[\gamma \frac{P}{\rho}\left(\frac{\gamma+1}{2}\right)^{\frac{(1+\gamma)}{(1-\gamma)}}\right]^{\frac{1}{2}} .
$$

In contrast, for $P_{a} / P>1 / \bar{P}_{c}$, when flow is subsonic, the orifice equation is

$$
\frac{d}{d t} m_{v}=C_{d} A_{V}\left[\frac{2 \gamma P \rho}{\gamma-1}\left(\frac{P_{a}}{P}\right)^{\frac{2}{\gamma}}\left(1-\left(\frac{P_{a}}{P}\right)^{\frac{(\gamma-1)}{\gamma}}\right)\right]^{\frac{1}{2}} .
$$

The burning rates are given by 


$$
\frac{d n}{d t}=\frac{1}{m_{i}} \rho_{u} S A
$$

By expanding mass and using the isentropic relation again, Eq. (4.9) can be simplified as

$$
\frac{d n}{d t}=\frac{A}{V_{i}}(\bar{P})^{\frac{1}{\gamma_{u}}} S
$$

A term is next added to account for burnt mass venting such that

$$
\frac{d n}{d t}=\frac{A}{V_{i}}(\bar{P})^{\frac{1}{\gamma_{u}}} S-\frac{d}{d t}\left(\frac{m_{v}}{m_{i}}\right)_{b} .
$$

Now, using Eq. (4.2) and separating terms using $E=e_{o}+\Delta e$,

$$
\frac{d}{d t}\left(\frac{m_{u}}{m_{i}}\left(e_{u o}+\Delta e_{u}\right)\right)+\frac{d}{d t}\left(\frac{m_{b}}{m_{i}}\left(e_{b o}+\Delta e_{b}\right)\right)+\left(e_{u o}+\Delta e_{u}\right) \frac{d}{d t}\left(\frac{m_{v}}{m_{i}}\right)=0 .
$$

By factoring out the energy at the initial states and rearranging,

$$
\frac{d}{d t}\left(\frac{m_{u}}{m_{i}} \Delta e_{u}\right)+\frac{d}{d t}\left(\frac{m_{b}}{m_{i}} \Delta e_{b}\right)+\Delta e_{u} \frac{d}{d t}\left(\frac{m_{v}}{m_{i}}\right)=-e_{u o}\left(\frac{d}{d t}\left(\frac{m_{b}}{m_{i}}\right)\right)-e_{b o} \frac{d}{d t}\left(\frac{m_{b}}{m_{i}}\right) .
$$

Equation (4.13) can be further reduced using the relation $\Delta e=C_{V}\left(T-T_{o}\right)$

$$
\begin{gathered}
C_{V u} \frac{d}{d t}\left(\frac{m_{u}}{m_{i}}\left(T_{u}-T_{o}\right)\right)+C_{V b} \frac{d}{d t}\left(\frac{m_{b}}{m_{i}}\left(T_{b}-T_{o}\right)\right)+C_{V u}\left(T_{u}-T_{o}\right) \frac{d}{d t}\left(\frac{m_{v}}{m_{i}}\right)= \\
\left(e_{u o}-e_{b o}\right) \frac{d}{d t}\left(\frac{m_{b}}{m_{i}}\right) .
\end{gathered}
$$

By separating terms for the original temperature and rearranging,

$$
\begin{gathered}
\frac{C_{V u} \frac{d}{d t}\left(\frac{m_{u}}{m_{i}} T_{u}\right)}{\left(C_{V u}\right) T_{i}}+\frac{C_{V b} \frac{d}{d t}\left(\frac{m_{b}}{m_{i}} T_{b}\right)}{\left(C_{V u}\right) T_{i}}+\frac{C_{V u} T_{u} \frac{d}{d t}\left(\frac{m_{v}}{m_{i}}\right)}{\left(C_{V u}\right) T_{i}}= \\
\frac{\left(\left(e_{u o}-e_{b o}\right)+T_{o}\left[C_{V b}-C_{V u}\right]\right)}{\left(C_{V u}\right) T_{i}} \frac{d}{d t}\left(\frac{m_{b}}{m_{i}}\right) .
\end{gathered}
$$

To simplify the equation, the dimensionless parameter $b$ is used such that

$$
\begin{gathered}
b=\frac{\left(\left(e_{u o}-e_{b o}\right)+T_{o}\left[C_{V b}-C_{V u}\right]\right)}{\left(C_{V u}\right) T_{i}} \\
\frac{d}{d t}\left(\frac{m_{u}}{m_{i}} \frac{T_{u}}{T_{i}}\right)+\frac{C_{V b}}{\left(C_{V u}\right)} \frac{d}{d t}\left(\frac{m_{b}}{m_{i}} \frac{T_{b}}{T_{i}}\right)=b \frac{d}{d t}\left(\frac{m_{b}}{m_{i}}\right)-\frac{T_{u}}{T_{i}} \frac{d}{d t}\left(\frac{m_{v}}{m_{i}}\right) .
\end{gathered}
$$

Now, using the ideal gas law and $R=C_{V}(\gamma-1)$, a simplified term can be found as follows:

$$
\begin{gathered}
\frac{d}{d t}\left(\frac{m_{u}}{m_{i}} * \frac{m_{i} P_{u} V_{u}}{m_{u} P_{i} V_{i}}\right)+\frac{\left(\gamma_{u}-1\right) R}{\left(\gamma_{b}-1\right) R} \frac{d}{d t}\left(\frac{m_{b}}{m_{i}} \frac{m_{i} P_{b} V_{b}}{m_{b} P_{i} V_{i}}\right)= \\
b \frac{d}{d t}\left(\frac{m_{b}}{m_{i}}\right)-\frac{m_{i} P_{u} V_{u}}{m_{u} P_{i} V_{i}} * \frac{d}{d t}\left(\frac{m_{v}}{m_{i}}\right),
\end{gathered}
$$




$$
\begin{gathered}
\frac{d}{d t}\left(\frac{P_{u} V_{u}}{P_{i} V_{i}}\right)+\frac{\left(\gamma_{u}-1\right)}{\left(\gamma_{b}-1\right)} \frac{d}{d t}\left(\frac{P_{b} V_{b}}{P_{i} V_{i}}\right)=b \frac{d}{d t}\left(\frac{m_{b}}{m_{i}}\right)-\frac{m_{i} P_{u} V_{u}}{m_{u} P_{i} V_{i}} * \frac{d}{d t}\left(\frac{m_{v}}{m_{i}}\right) \\
\frac{d}{d t}\left(\bar{P}_{u}\left(1-\eta^{3}\right)\right)+\frac{\left(\gamma_{u}-1\right)}{\left(\gamma_{b}-1\right)} \frac{d}{d t}\left(\bar{P}_{b} \eta^{3}\right)=b \frac{d}{d t}\left(\frac{m_{b}}{m_{i}}\right)-\frac{\left(P_{i} C\right)^{\frac{1}{\gamma_{u}}}}{\left(P_{u} C\right)^{\frac{1}{\gamma_{u}}}} \bar{P}_{u} * \frac{d}{d t}\left(\frac{m_{v}}{m_{i}}\right) \\
\frac{d}{d t}\left(\bar{P}_{u}\left(1-\eta^{3}\right)\right)+\frac{\left(\gamma_{u}-1\right)}{\left(\gamma_{b}-1\right)} \frac{d}{d t}\left(\bar{P}_{b} \eta^{3}\right)=b \frac{d}{d t}\left(\frac{m_{b}}{m_{i}}\right)-\bar{P}_{u}^{1-\frac{1}{\gamma_{u}}} \frac{d}{d t}\left(\frac{m_{v}}{m_{i}}\right) .
\end{gathered}
$$

By rearranging Eqs. (4.1) and (4.20) into Eqs. (4.21) and (4.22), Cramer's rule may be used to find equations for $d \bar{P} / d t$ and $d \eta^{3} / d t$,

$$
\begin{aligned}
& \frac{\left(1-\eta^{3}\right) \bar{P}^{\left(\frac{1}{\gamma_{u}}-1\right)}}{\gamma_{u}} \frac{d \bar{P}}{d t}-\bar{P}^{\left(\frac{1}{\gamma_{u}}\right)} \frac{d \eta^{3}}{d t}=-\frac{d n}{d t}-\frac{d}{d t}\left(\frac{m_{v}}{m_{i}}\right), \\
& {\left[1+\eta^{3}\left(\gamma_{e}-1\right)\right] \frac{d \bar{P}}{d t}+\bar{P}\left(\gamma_{e}-1\right) \frac{d \eta^{3}}{d t}=b \frac{d n}{d t}+\bar{P}^{\left(1-\frac{1}{\gamma_{u}}\right)} \frac{d}{d t}\left(\frac{m_{v}}{m_{i}}\right)} \\
& {\left[\begin{array}{cc}
\frac{\left(1-\eta^{3}\right) \bar{P}^{\left(\frac{1}{\gamma_{u}}-1\right)}}{\gamma_{u}} & -\bar{P}^{\left(\frac{1}{\gamma_{u}}\right)} \\
1+\eta^{3}\left(\gamma_{e}-1\right) & \bar{P}\left(\gamma_{e}-1\right)
\end{array}\right]\left[\begin{array}{c}
\frac{d \bar{P}}{d t} \\
\frac{d \eta^{3}}{d t}
\end{array}\right]=\left[\begin{array}{c}
-\frac{d n}{d t}-\frac{d}{d t}\left(\frac{m_{v}}{m_{i}}\right) \\
b \frac{d n}{d t}+\bar{P}^{\left(1-\frac{1}{\gamma_{u}}\right)} \frac{d}{d t}\left(\frac{m_{v}}{m_{i}}\right)
\end{array}\right],} \\
& {\left[\begin{array}{ll}
A_{11} & A_{12} \\
A_{21} & A_{22}
\end{array}\right]\left[\begin{array}{l}
\frac{d \bar{P}}{d t} \\
\frac{d \eta^{3}}{d t}
\end{array}\right]=\left[\begin{array}{l}
B_{1} \\
B_{2}
\end{array}\right]} \\
& A_{11}=\frac{\left(1-\eta^{3}\right) \bar{P}^{\left(\frac{1}{\gamma_{u}}-1\right)}}{\gamma_{u}} \text {, } \\
& A_{12}=-\bar{P}^{\left(\frac{1}{\gamma_{u}}\right)} \text {, } \\
& A_{21}=1+\eta^{3}\left(\gamma_{e}-1\right) \text {, } \\
& A_{22}=\bar{P}\left(\gamma_{e}-1\right) \text {, } \\
& B_{1}=-\frac{d n}{d t}-\frac{d}{d t}\left(\frac{m_{v}}{m_{i}}\right), \\
& B_{2}=b \frac{d n}{d t}+\bar{P}^{\left(1-\frac{1}{\gamma_{u}}\right)} \frac{d}{d t}\left(\frac{m_{v}}{m_{i}}\right) . \\
& \gamma_{e}=\frac{\gamma_{u}-1}{\gamma_{b}-1}
\end{aligned}
$$




$$
\begin{gathered}
b=\gamma_{e} \bar{P}_{f}-1, \\
\frac{d \bar{P}}{d t}=\frac{B_{1} A_{22}-B_{2} A_{12}}{A_{11} A_{22}-A_{12} A_{21}}, \\
\frac{d \eta^{3}}{d t}=\frac{B_{2} A_{12}-B_{1} A_{22}}{A_{11} A_{22}-A_{12} A_{21}} .
\end{gathered}
$$

As a result, by using Cramer's rule, Eqs. (4.34) and (4.35) are comprised of Eqs. (4.26) - (4.33). Next the orifice equations are employed. For $P_{a} / P \leq 1 / \bar{P}_{c}$,

$$
\frac{d}{d t}\left(\frac{m_{v}}{m_{i}}\right)=C_{d} \frac{A_{V} \rho}{m_{i}}\left[\gamma \frac{P}{\rho}\left(\frac{\gamma+1}{2}\right)^{\frac{(1+\gamma)}{(1-\gamma)}}\right]^{\frac{1}{2}}
$$

while for $P_{a} / P>1 / \bar{P}_{c}$

$$
\frac{d}{d t} \frac{m_{v}}{m_{i}}=\frac{C_{d} A_{V}}{m_{i}}\left[\frac{2 \gamma P \rho}{\gamma-1}\left(\frac{P_{a}}{P}\right)^{\frac{2}{\gamma}}\left(1-\left(\frac{P_{a}}{P}\right)^{\frac{(\gamma-1)}{\gamma}}\right)\right]^{\frac{1}{2}} .
$$

The respective burning rate equations are

$$
\begin{gathered}
\frac{d n}{d t}=\frac{A}{V_{i}}(\bar{P})^{\frac{1}{\gamma_{u}}} S, \\
\frac{d n}{d t}=\frac{A}{V_{i}}(\bar{P})^{\frac{1}{\gamma_{u}}} S-\frac{d}{d t}\left(\frac{m_{v}}{m_{i}}\right)_{b} .
\end{gathered}
$$

Altogether, Eqs. (4.35) - (4.39) are the fundamental governing equations used in this solver.

\subsection{Flame Shape Equations}

As the flame velocity and the burning rate are determined by the shape and size of the burning volume, accurate predictions of overpressure rely on a precise flame shape estimation. Equations for central and rear ignition are shown below. These are based on the shapes shown in Fig. 7. A term is included to estimate area of the section of the ellipsoid that has extended past the vent, as this no longer affects the burning rate inside the volume.

\subsubsection{Central Ignition}

The shape of a flame in central ignition is given by a half-ellipsoid, half-circle; see Fig. 7. The area of this shape is calculated as 
with $r$ defined as

$$
\frac{A}{V_{i}}=\left(\frac{2 \pi}{V_{i}}\right)\left[\left\{\frac{\left(a_{c} b_{c}\right)^{1.6}+\left(c_{c} b_{c}\right)^{1.6}+\left(a_{c} c_{c}\right)^{1.6}}{3}\right\}^{\frac{1}{1.6}}+r^{2}\right]
$$

$$
r=\left[\frac{3 \bar{V} V_{i}}{2 \pi\left(\frac{3 W}{2 H}+1\right)}\right]^{\frac{1}{3}}
$$

After the flame reaches the vent, there is an ellipsoid removed from the volume. A term to account for this is added:

$$
\begin{gathered}
\frac{A}{V_{i}}=\left(\frac{2 \pi}{V_{i}}\right)\left[\left\{\frac{\left(a_{c} b_{c}\right)^{1.6}+\left(c_{c} b_{c}\right)^{1.6}+\left(a_{c} c_{c}\right)^{1.6}}{3}\right\}^{\frac{1}{1.6}}+r^{2}\right. \\
\left.-0.5 a_{c} b_{c}\left\{\frac{\operatorname{Sin}^{-1} e-\operatorname{Sin}^{-1} e_{c}}{e}+\frac{b_{c}}{a_{c}}-\left(1-\frac{h_{c}}{a_{c}}\right) \sqrt{1-e_{c}^{2}}\right\}\right] .
\end{gathered}
$$

Here $r$ is found from the equation

$$
\frac{2}{3} \pi r^{3}+\frac{1}{2} \pi W r^{2}-\frac{\pi W H^{2}}{54}-\bar{V} V_{i}=0
$$

The variables in these terms are given by

$$
\begin{gathered}
a_{c}=\frac{3 W r}{2 H}, \\
b_{c}=c_{c}=r \\
e=\sqrt{1-\frac{b_{c} c_{c}}{a_{c}^{2}}} \\
e_{c}=e\left(1-\frac{h_{c}}{a_{c}}\right) .
\end{gathered}
$$

\subsubsection{Rear Ignition}

With rear ignition, the flame is modeled as a half ellipse. The area equation for this geometry is

$$
\begin{gathered}
\frac{A}{V_{i}}=\left(\frac{2 \pi}{V_{i}}\right)\left[\left\{\frac{\left(a_{c} b_{c}\right)^{1.6}+\left(c_{c} b_{c}\right)^{1.6}+\left(a_{c} c_{c}\right)^{1.6}}{3}\right\}^{\frac{1}{1.6}}\right], \\
r=\left[\frac{3 \bar{V} V_{i} H}{6 \pi W}\right]^{\frac{1}{3}} .
\end{gathered}
$$

A term to account for the ellipsoidal cap, similar to that for central ignition, is then added to yield 


$$
\begin{gathered}
\frac{A}{V_{i}}=\left(\frac{2 \pi}{V_{i}}\right)\left[\left\{\frac{\left(a_{c} b_{c}\right)^{1.6}+\left(c_{c} b_{c}\right)^{1.6}+\left(a_{c} c_{c}\right)^{1.6}}{3}\right\}^{\frac{1}{1.6}}\right. \\
\left.-0.5 a_{c} b_{c}\left\{\frac{\operatorname{Sin}^{-1} e-\operatorname{Sin}^{-1} e_{c}}{e}+\frac{b_{c}}{a_{c}}-\left(1-\frac{h_{c}}{a_{c}}\right) \sqrt{1-e_{c}^{2}}\right\}\right], \\
r=\sqrt{\left[\frac{\bar{V} V_{i}}{\pi W}+\frac{H^{2}}{27}\right]} .
\end{gathered}
$$

Similar to central ignition, here the variables are given by

$$
\begin{gathered}
a_{R}=\frac{3 W_{r}}{H}, \\
B_{R}=C_{R}=r, \\
h_{r}=a_{R}-W, \\
e=\sqrt{1-\frac{b_{R} c_{r}}{a_{R}^{2}},} \\
e_{R}=e\left(1-\frac{h_{R}}{a_{R}}\right) .
\end{gathered}
$$




\section{Simulations}

In order to construct a model that is both accurate and computationally inexpensive, several simplifying assumptions have to be made. First, the geometry should be simplified. Specifically, cuboid enclosures with a vent located at one end are considered. Obstacles within the enclosure and acoustic effects are not considered in this thesis. Ignition occurs in the center of the cuboid or on the center of the rear wall of the cuboid. In order to avoid problems with an initial flame radius of zero, a non-zero initial value is used in the program. This volume of burnt gas is small enough to not affecting the overall pressure in the enclosure. The shape of the flame is considered as (i) a sphere when the vent is closed, and (ii) a half-sphere, half-ellipsoid, as discussed in Sec. 2, when the vent is open. The vent opening process is considered to be complete and instantaneous.

Second, several assumptions are made regarding the gasses. Prior to ignition, the gas is considered as a homogeneous mixture. All gaseous mixtures are assumed to obey the ideal gas law and the expansion and compression of the unburnt gas are assumed to be isentropic. In addition, all gas properties are considered to be uniform along with the pressure distribution within the enclosure. By using these assumptions, the zero-dimensional model discussed in this theses may be able to estimate the complex process described.

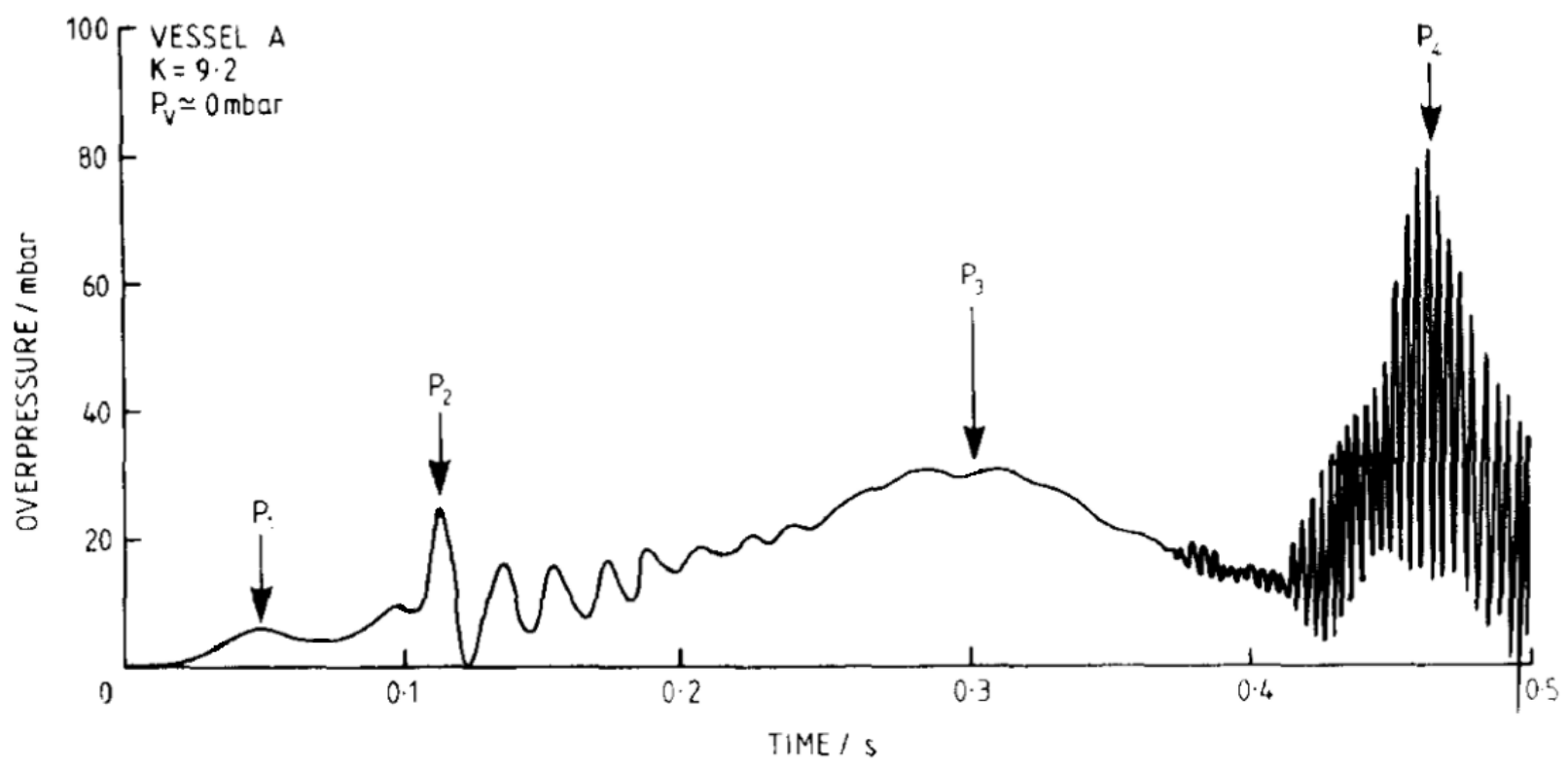

Figure 13- Typical pressure spikes of a vented explosion (Cooper \& FairWeather, 1986) 
Figure 13 shows the standard pattern of pressure spikes in vented explosions. The four peaks are identified as follows. Specifically, $\mathrm{P}_{1}$ shows the point where the venting began due to overcoming the vent pressure; $\mathrm{P}_{2}$ shows where the flame reached the vent and burnt gasses started venting; $\mathrm{P}_{3}$ shows the point when fuel begins to be depleted and the flame area decreases; and $\mathrm{P}_{4}$ shows when acoustic effects become prominent and the remaining fuel burns rapidly. In this thesis, only the first two peaks are investigated. The second peak is significantly larger for reasonable venting pressures, which are considered here. The purpose of including the first peak is to estimate the timing and magnitude of the second more accurately.

In order to estimate the effects of an initially closed vent, no venting is assumed until the breaking pressure is reached. To verify the accuracy of this assumption, the pressure spikes for various pressures are compared to the experimental data (Bao, et al., 2016). While the maximum pressure is pre-determined for this simulation, having reasonable results for time and shape of the spike improves accuracy of the final result.

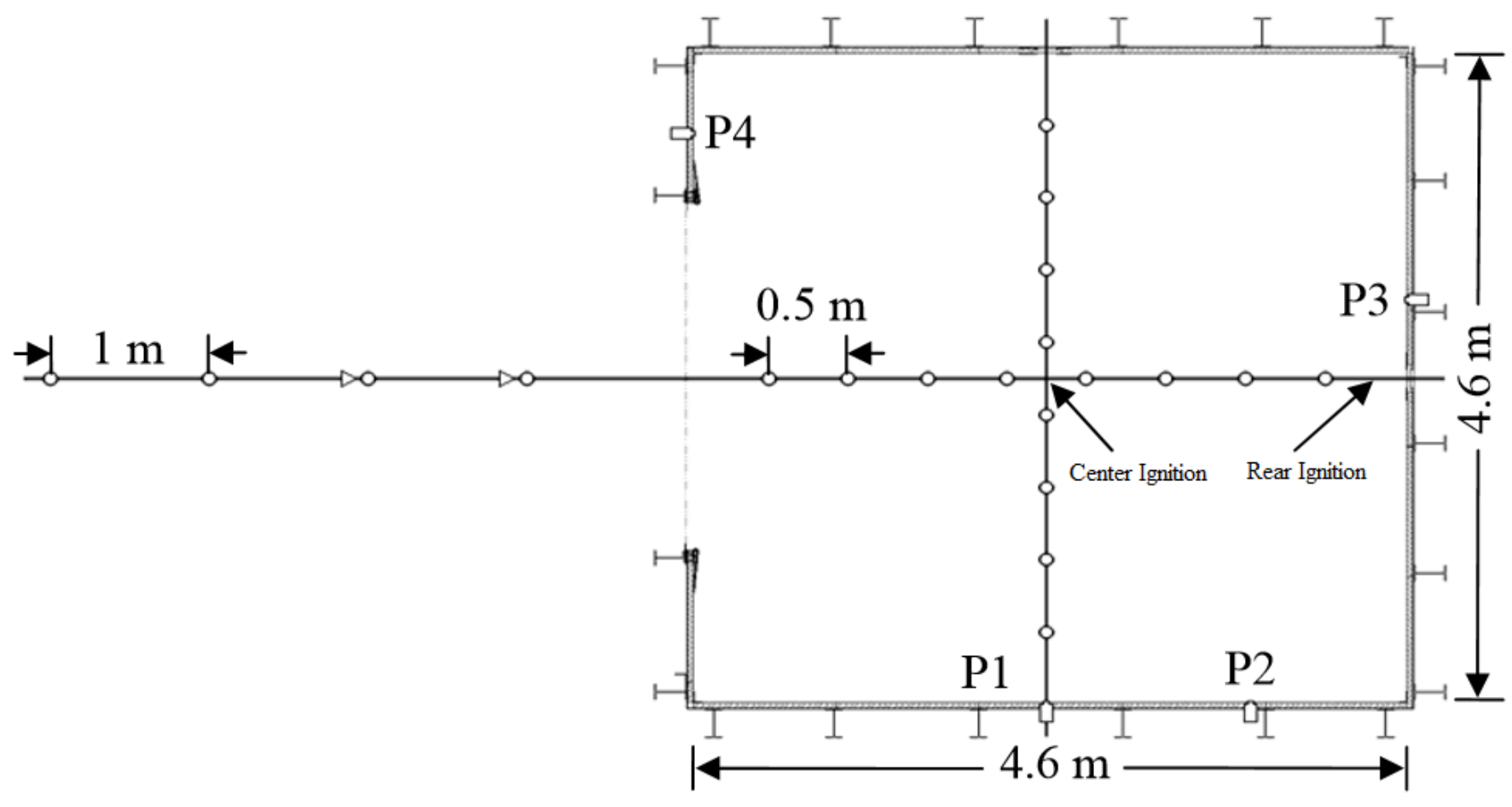

Figure 14-Experimental setup replicated with the EVA solver (Bauwens, et al., 2008) 


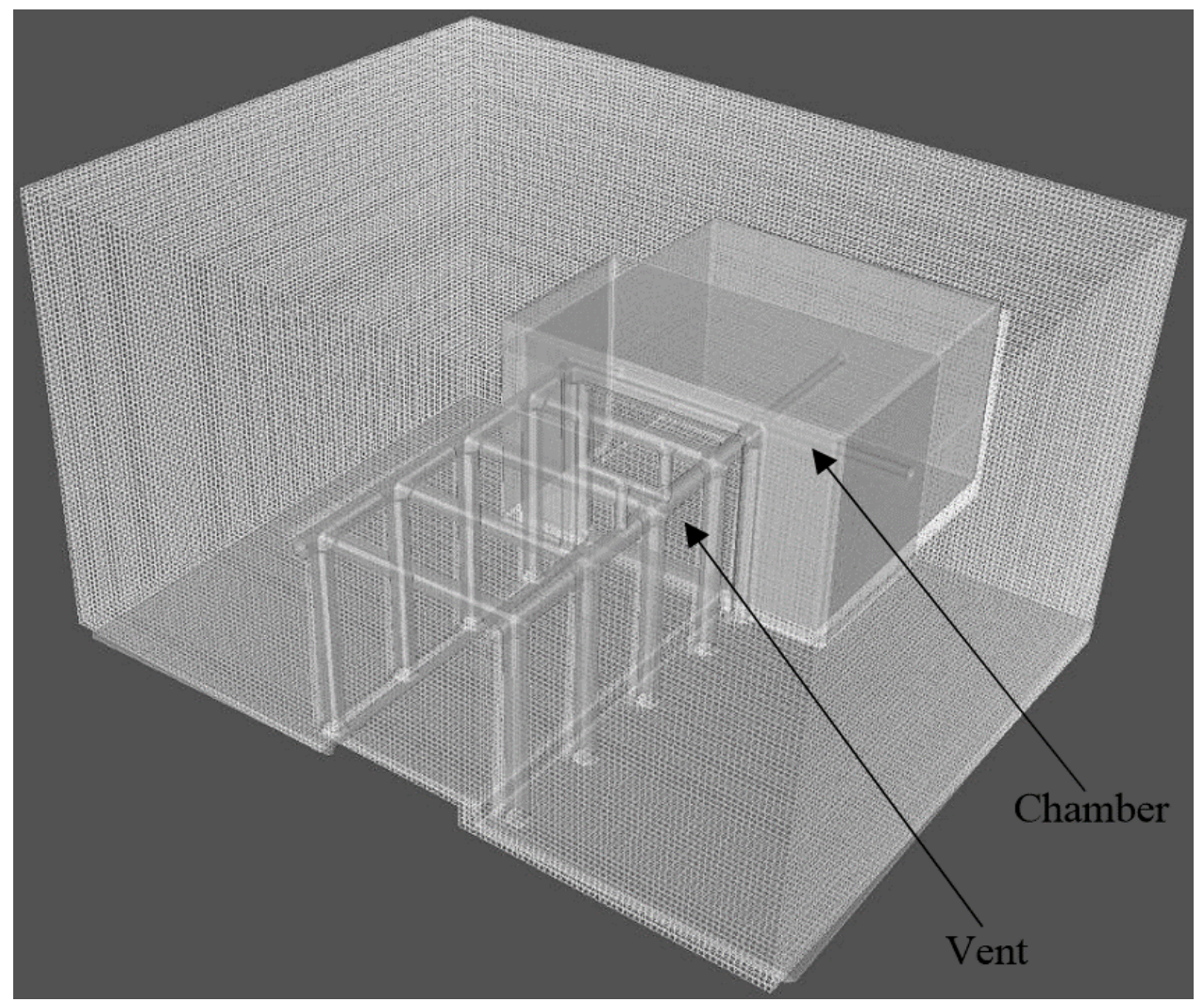

Figure 15- The geometry of the computational domain used by (Bauwens, et al., 2008)

The geometries to be simulated are based on the experiments (Bauwens, et al., 2008). The experimental geometry can be seen in Fig. 14. Bauwens et al (2008) also used a CFD model to calculate the pressure in the same geometries. The simulations were performed using a solver built using the OpenFOAM CFD toolbox. The code is based on a Large Eddy Simulation solver of the Naviers-Stokes equations. The geometry consists of $10^{6}$ cells and requires the inclusion of a 10x6x7.6 m external volume. The configuration of the model is presented in Fig.15.

\begin{tabular}{|c|c|c|c|c|}
\hline Simulation \# & 1 & 2 & 3 & 4 \\
\hline CFD Equivalence ratio & 1 & 1 & 1 & 1 \\
\hline $\begin{array}{c}\text { Experiment and EVA } \\
\text { equivalence Ratio }\end{array}$ & 0.965 & 0.965 & 1 & 1.094 \\
\hline Vent size (m2) & 2.7 & 2.7 & 5.4 & 5.4 \\
\hline Vent location & Rear & Center & Rear & Center \\
\hline Enclosure Volume(m3) & 157 & 157 & 157 & 157 \\
\hline Discharge Coefficient & 0.6 & 0.6 & 0.6 & 0.6 \\
\hline
\end{tabular}

Table 1- Inputs for 4 simulations completed using EVA 
The EVA program is used to calculate the initial pressure spikes of the four different geometries. Various input parameters are listed in Table 1. Experimental limitations caused the equivalence ratios for the experiments and the CFD model vary slightly. Both center and rear ignitions are considered. Here, rear ignition, which could be caused by a light switch on the far wall of a room in a practical situation, is a more likely ignition location. Center ignition is also possible, for example, from an appliance near the center of a room, and it should be considered on a separate, since the pressure spike behaves differently in that case. This is because the flame reaches the outside of the enclosure before all the fuel is burned.

These two experimental studies were chosen to simulate with the EVA for several reasons. First, both cases are devoted for relatively realistic situations. Indeed, methane, which comprises $95 \%$ of natural gas, is the most common cause of residential explosions. A cuboid geometry is also much more likely to be encountered in reality than a sphere or cylinder. Considering methane in a cuboid also allows the two major contributions from the works (Ugarte, et al., 2016) and (Sezer, et al., 2016) to be utilized completely. The experiments (Bao, et al., 2016) were chosen specifically to allow verification of the assumptions used to calculate venting pressures. Finally, the work (Bauwens, et al., 2008) was used because the accuracy of the EVA can be compared to that of a full CFD model, as EVA is a less complex alternative to full CFD models.

Additionally, two parametric studies are included, for various vent sizes and equivalence ratios. The inputs for these studies are listed in Table 2. Each study is done for both central and rear ignitions. Experimental and CFD data from (Bauwens, et al., 2008) is included in the plots for reference.

\begin{tabular}{|c|c|c|}
\hline Varying Parameter & Venting Area & Equivalence Ratio \\
\hline Equivalence Ratio & 1 & $.7-1.2$ \\
\hline Vent size $\left(\mathrm{m}^{2}\right)$ & $0-12$ & 5.4 \\
\hline Enclosure Volume $\left(\mathrm{m}^{3}\right)$ & 157 & 157 \\
\hline Discharge Coefficient & 0.6 & 0.6 \\
\hline
\end{tabular}

Table 2- Inputs for two parametric studies completed with EVA 


\section{Results and Discussion}

\subsection{Comparisons to Experimental Data}

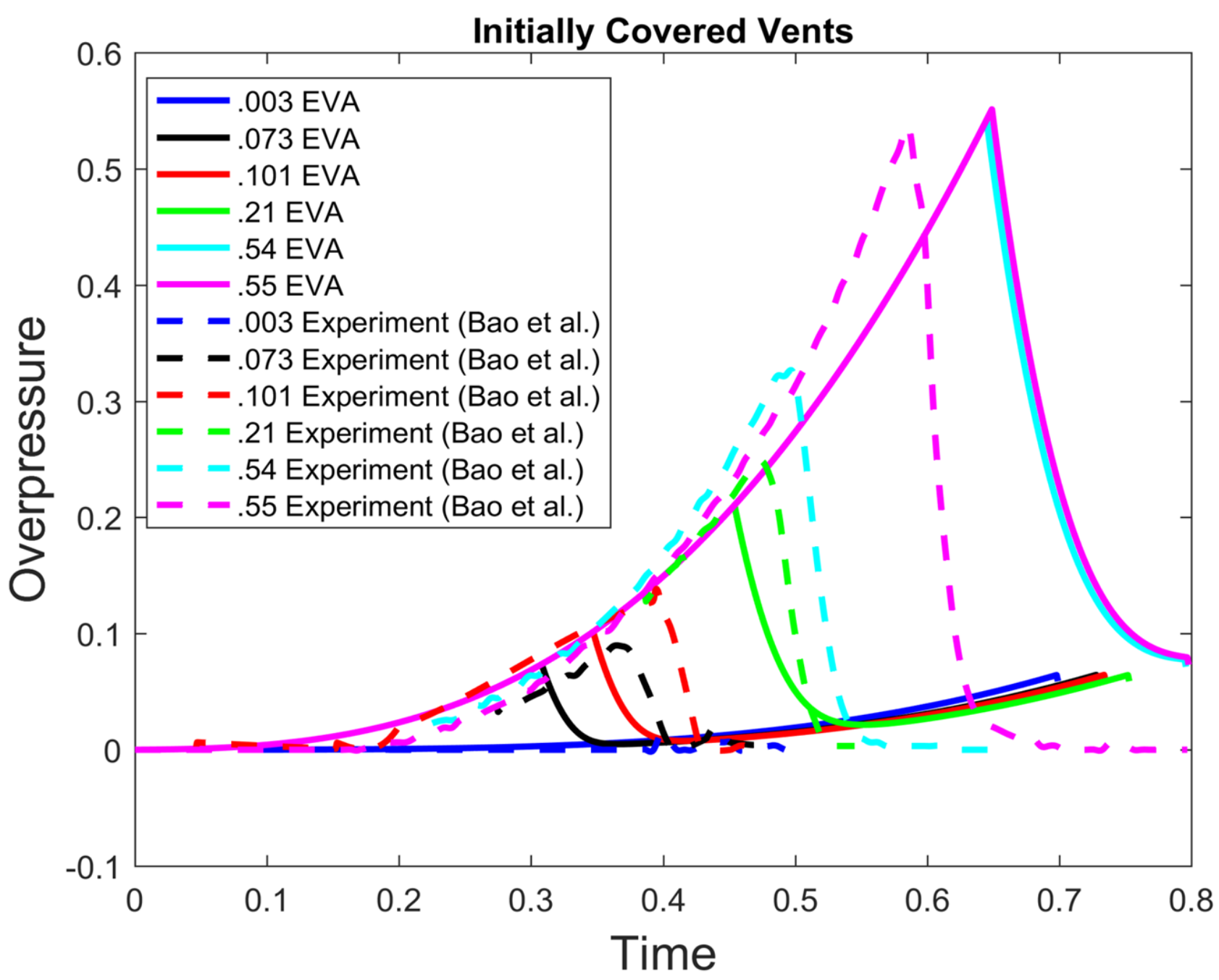

Figure 16- Overpressure versus time for various venting pressures: the EVA solution and experimental data from (Bao, et al., 2016)

Figure 16 shows that the pressure spike from the internal pressure reaching the venting pressure and then venting. When compared to the experiments (Bao, et al., 2016), the timing of the vent cover breaking is within about 0.1 seconds, which is a reasonable result for this purpose. The errors in venting pressure and timing are largely the outcome of difficulty in determining the pressure at which the vent cover breaks. Bao et al (2016) used glass vent covers that were intended to shatter at the designated pressure. While these venting pressures vary, the nature of the glass breaking allows the assumption of complete and instantaneous vent opening to work 
well. As justified by Fig. 16, the time when venting starts can be estimated accurately enough when studied by itself. This method is now used to simulate the effects on the four geometries from Table 1.

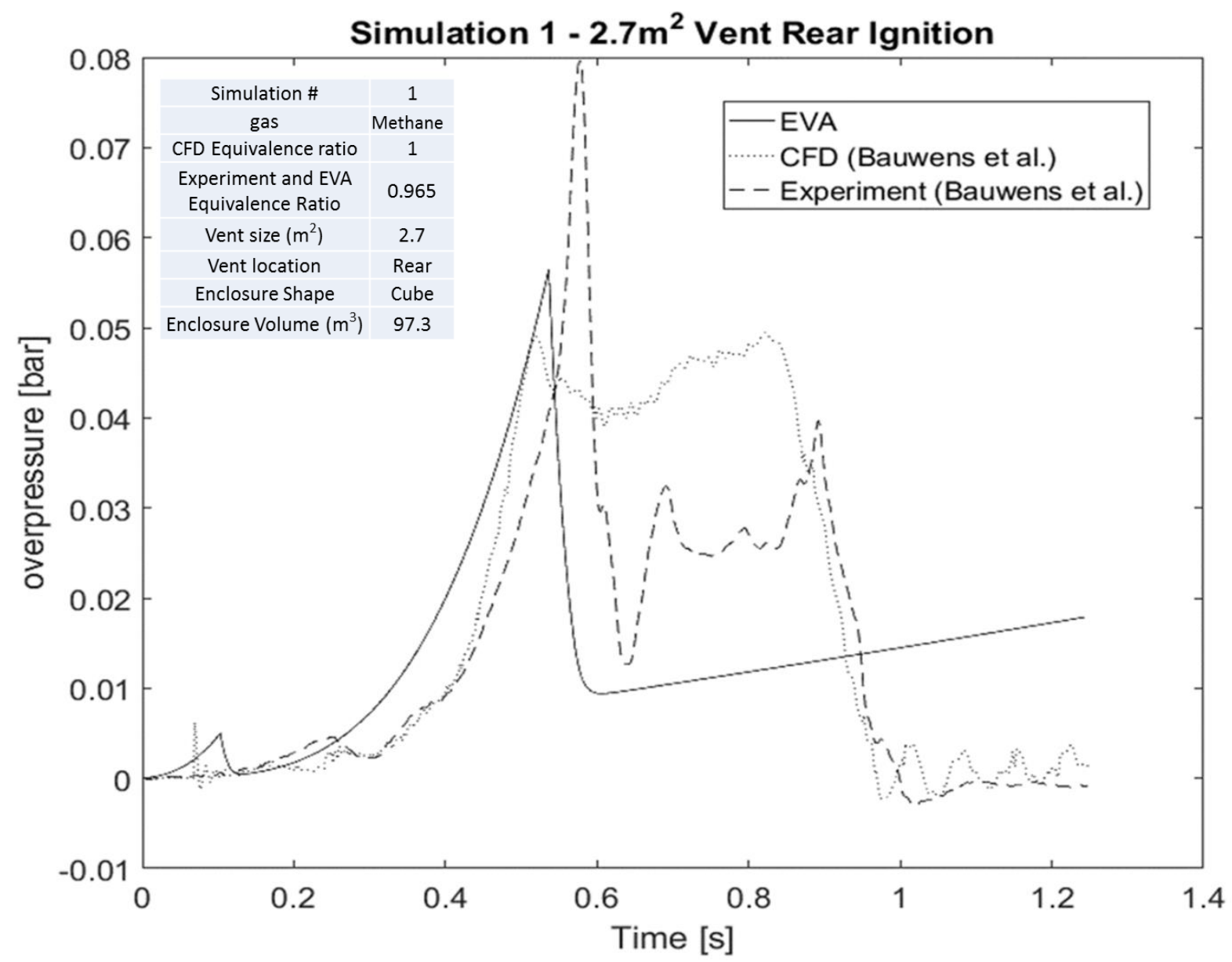

Figure 17- Overpressure versus time for $2.7 \mathrm{~m}^{2}$ vent with rear ignition

In the first simulation, Fig. 17, the error in the timing of the venting begins grows due to a more complex problem geometry. However, the timing of the first pressure spike is estimated accurately. The pressure spike in the experimental data is seen to be significantly greater than the EVA or CFD simulations. However, the goal of this simulation is to be comparable or better than the CFD model. As can be seen, the EVA is slightly more accurate than the CFD model at estimating the magnitude of the spike. The simulation also predicts the large pressure drop after the initial spike, which the CFD model does not. 


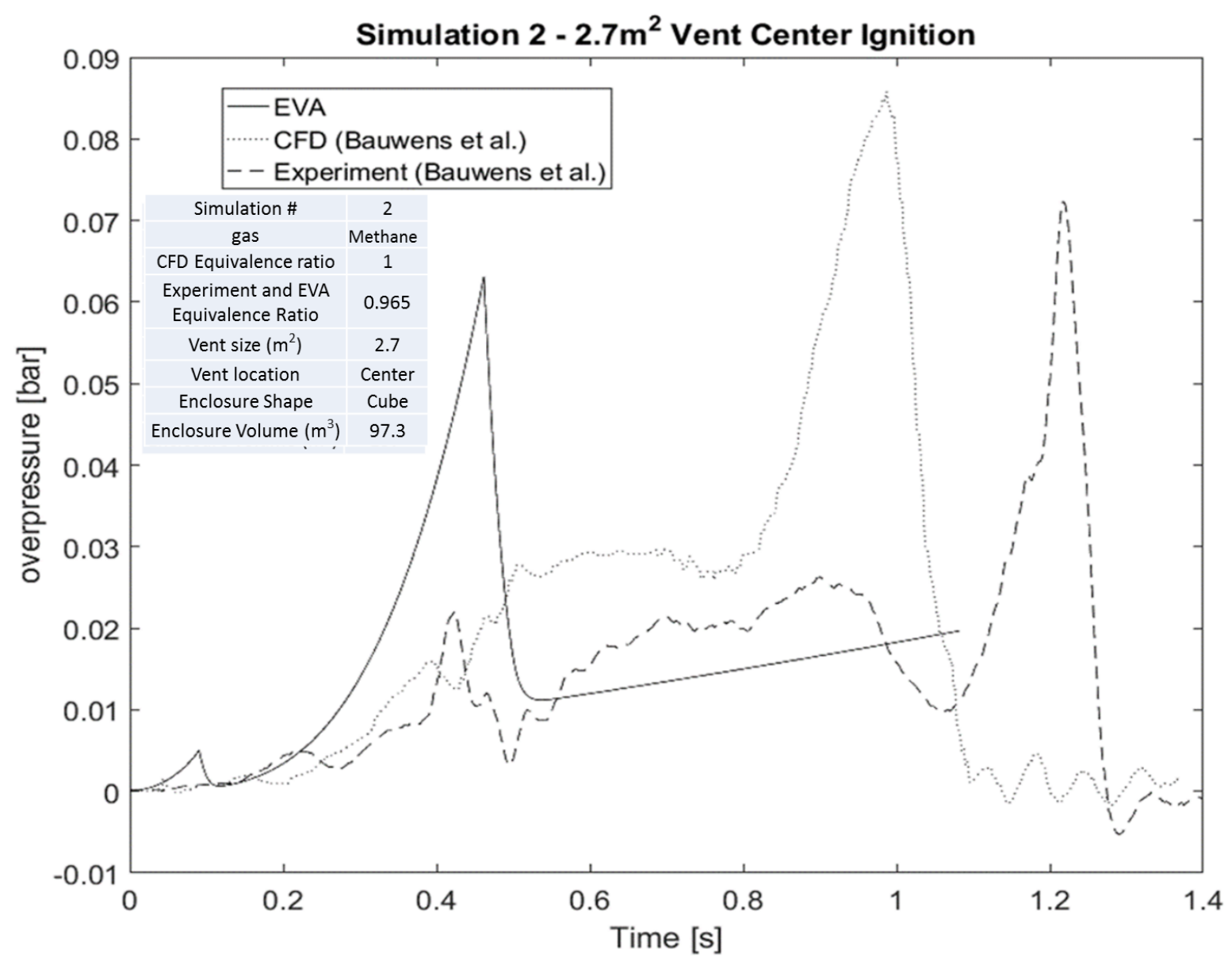

Figure 18- Overpressure versus time for $2.7 \mathrm{~m}^{2}$ vent with center ignition

The second simulation, Fig. 18, represents the largest discrepancy between the EVA and the experimental data. While the time of the spike is accurate, the magnitude of the pressure spike is about $1 / 3$ of what is predicted by the EVA. The lack of a large initial pressure spike is predicted accurately by the CFD model. This may be due to acoustic interactions which are accounted for by the CFD model, but omitted by the EVA. Figure 18 also shows a second large pressure spike in the experimental data, which is predicted by the CFD model. This second spike is characteristic of some vented explosions, as illustrated previously in Fig. 13. This spike is caused by unburnt gas in the enclosure burning rapidly after the flame has reached the vent. This spike is observed in central ignition, but not rear ignition, because when the flame is ignited in the rear it travels the length of the enclosure to reach the vent, burning most of the fuel. Central ignition, however, can leave a large amount of unburnt gas in the rear of the enclosure. Due to 
the acoustic effects and large surface area of the flame, this remaining gas may burn rapidly creating a large pressure spike which may be larger than the first.

Figure 19 shows simulation 3, which is once again for central ignition, but with a larger vent size. As is expected for rear ignition, here is no second large pressure spike. The CFD model and the EVA both under predict the pressure spike, however the EVA is more accurate. The large pressure spike and immediate drop are due to the effects of the external explosion preventing venting, and its acoustic effects.

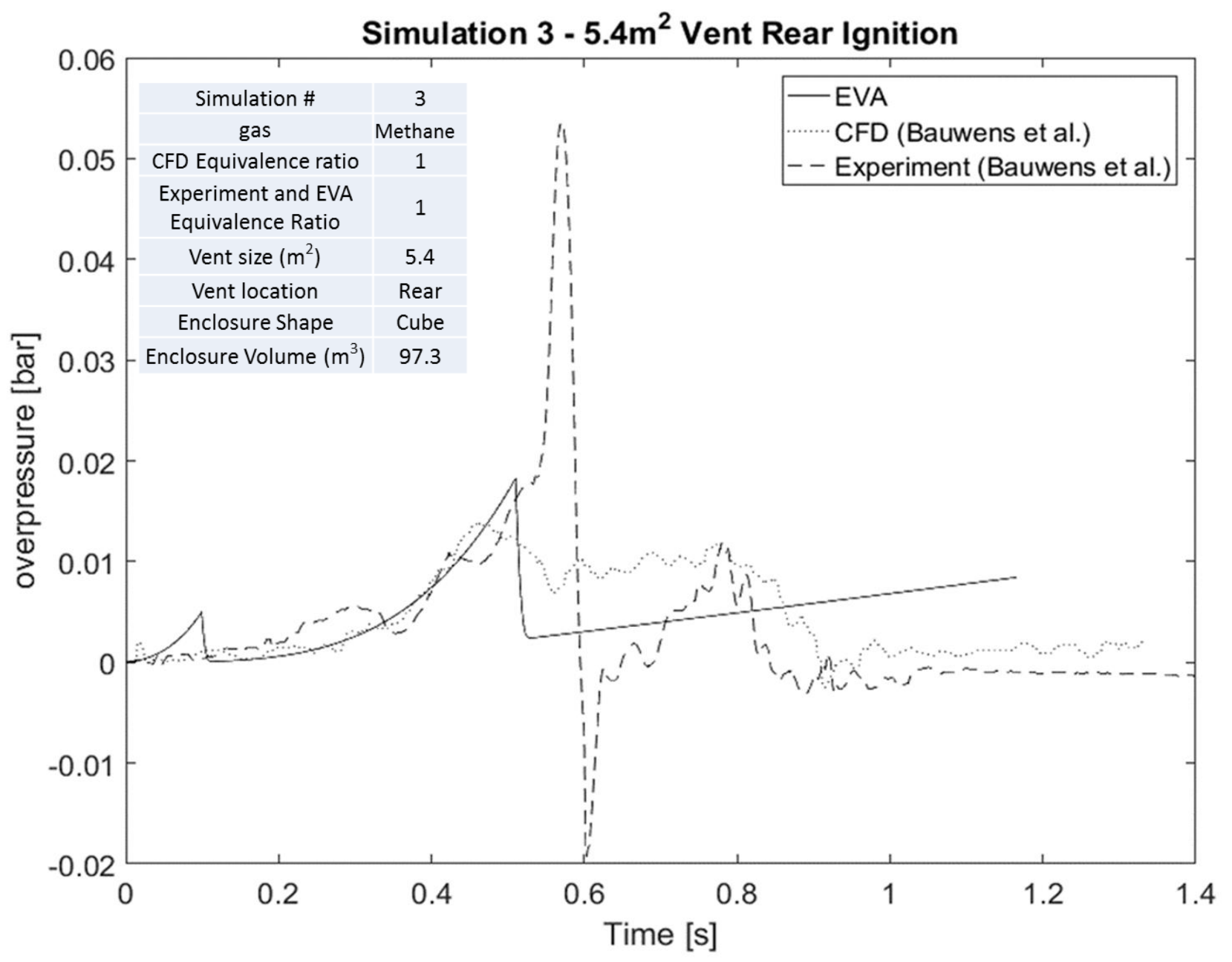

Figure 19- Overpressure versus time for $5.4 \mathrm{~m}^{2}$ vent with rear ignition

Simulation 4, Fig. 20, shows results where the EVA is significantly more accurate than the CFD model at predicting the initial pressure spike. However, the EVA does not consider the second pressure spike, which is a characteristic of central ignition. The second pressure spike 
here is larger than the first one. This illustrates that while the EVA is capable of predicting part of the process, more work is needed to improve its accuracy for more complex interactions.

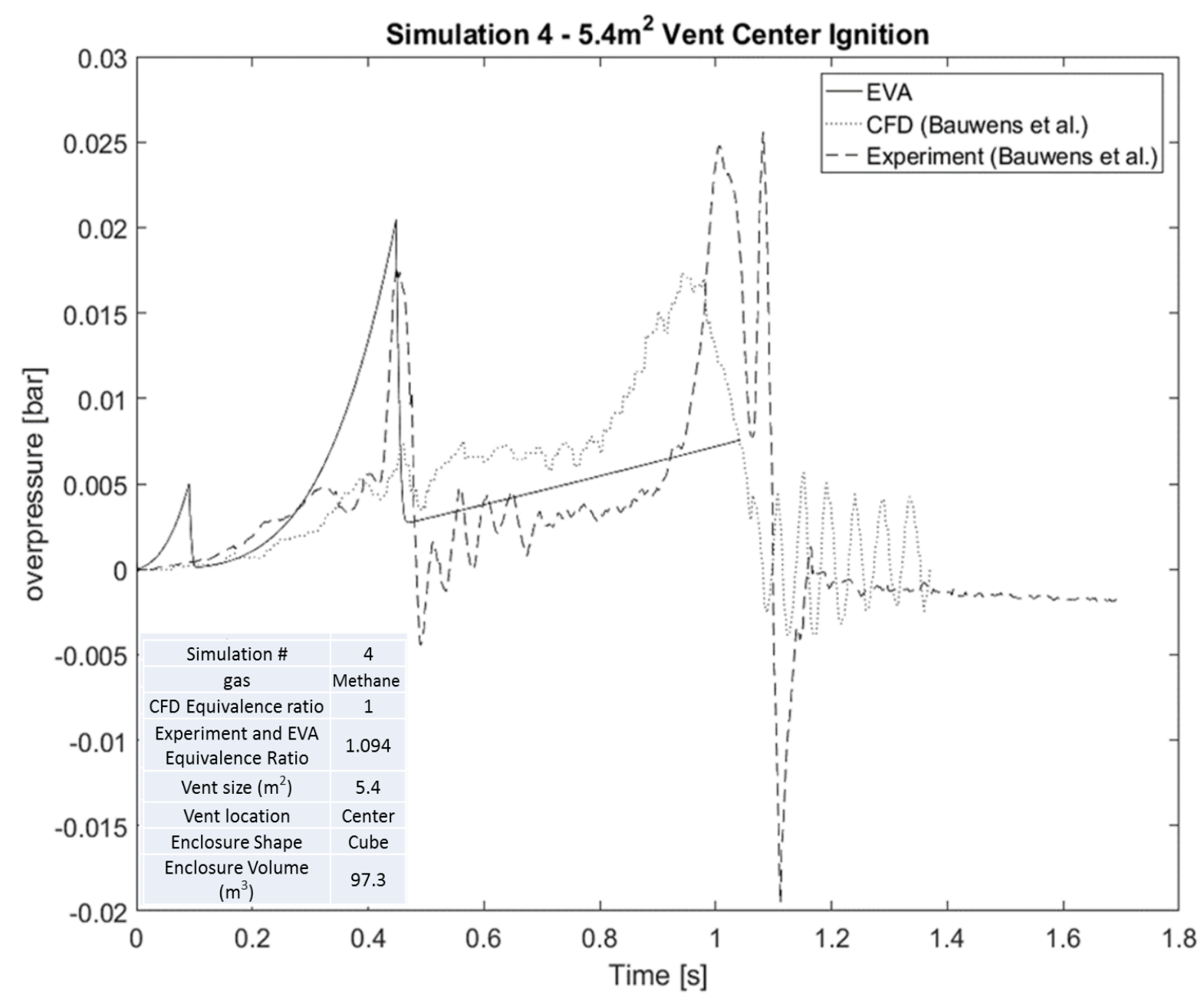

Figure 20- Overpressure versus time for $5.4 \mathrm{~m}^{2}$ vent with center ignition

These four simulations using the EVA, undertaken to reflect the experiments (Bauwens, et al., 2008), are completed with the goal of being as, if not more, accurate as the full CFD model. This is done successfully for the rear ignition geometries. As mentioned previously, the EVA did not consider the interactions that caused the second pressure spike, which is present for central ignitions. When considering only the first pressure spike, the accuracy is relatively poor for the small vent size, but it is good enough for the large vent size. However, the second pressure spike is the larger of the two and further work is needed in order to predict it accurately. 
Table 3 shows the accuracy of the CFD model and that of the EVA to predict the first pressure spike. The second pressure spike is not considered in this table.

\begin{tabular}{|c|c|c|c|c|}
\hline Simulation \# & 1 & 2 & 3 & 4 \\
\hline $\begin{array}{c}\text { Vent Size }\left(\mathrm{m}^{2}\right) \\
\text { Vent Location }\end{array}$ & 2.7 & 2.7 & 5.4 & 5.4 \\
\hline $\begin{array}{c}\text { EVA max } \\
\text { Rear }\end{array}$ & 0.056489 & 0.063106 & 0.018259 & 0.02041 \\
\hline $\begin{array}{c}\text { CFD max } \\
\text { pressure (bar) }\end{array}$ & 0.049414 & 0.0293 & 0.013969 & 0.0073 \\
\hline $\begin{array}{c}\text { Experimental max } \\
\text { pressure (bar) }\end{array}$ & 0.079572 & 0.0219 & 0.05359 & 0.0177 \\
\hline $\begin{array}{c}\text { EVA error } \\
\text { CFD Error }\end{array}$ & $29.0 \%$ & $188.2 \%$ & $65.9 \%$ & $15.3 \%$ \\
\hline
\end{tabular}

Table 3-Maximum pressure and error of first pressure spike

\subsection{Parametric Studies}

A considerable advantage of this type of solver is the reduction of computing power required. This allows for parametric studies to be completed easily and quickly. This is helpful when determining the required size of a venting area, or the most dangerous equivalency ratio. This would be almost impossible to do with CFD model mainly because of the computing time required and, in part, partially because modifying the code of a CFD program may be difficult.

First, the effects of various vent sizes are considered. The vent varies in the range of 0-12 $\mathrm{m}^{2}$. This is done for an equivalence ratio of 1.0, in a $93.7 \mathrm{~m}^{3}$ enclosure, which is the same size as the experiments (Bauwens et al., 2008). Therefore, the two CFD and experimental data is included in order to show the accuracy of this model.

Figure 21 shows how rapidly the pressure spike decreases as the vent area increases. It can be seen that an overpressure of $1 \mathrm{~atm}$, which may destroy most buildings, can be avoided with a $0.5 \mathrm{~m}^{2}$ venting area for a $93.7 \mathrm{~m}^{3}$ enclosure. At an overpressure of approximately $0.1 \mathrm{~atm}$, fatal injuries may occur. The plot shows that in order to avoid this, the vent size must be above 2 $\mathrm{m}^{2}$. In order to implement a reasonable factor of safety, a vent area of between $4 \mathrm{~m}^{2}$ and $6 \mathrm{~m}^{2}$, 
may be used. Finally, this plot also illustrates a diminishing return, and that a vent area of above $8 \mathrm{~m}^{2}$ does not improve safety enough to justify the costs.

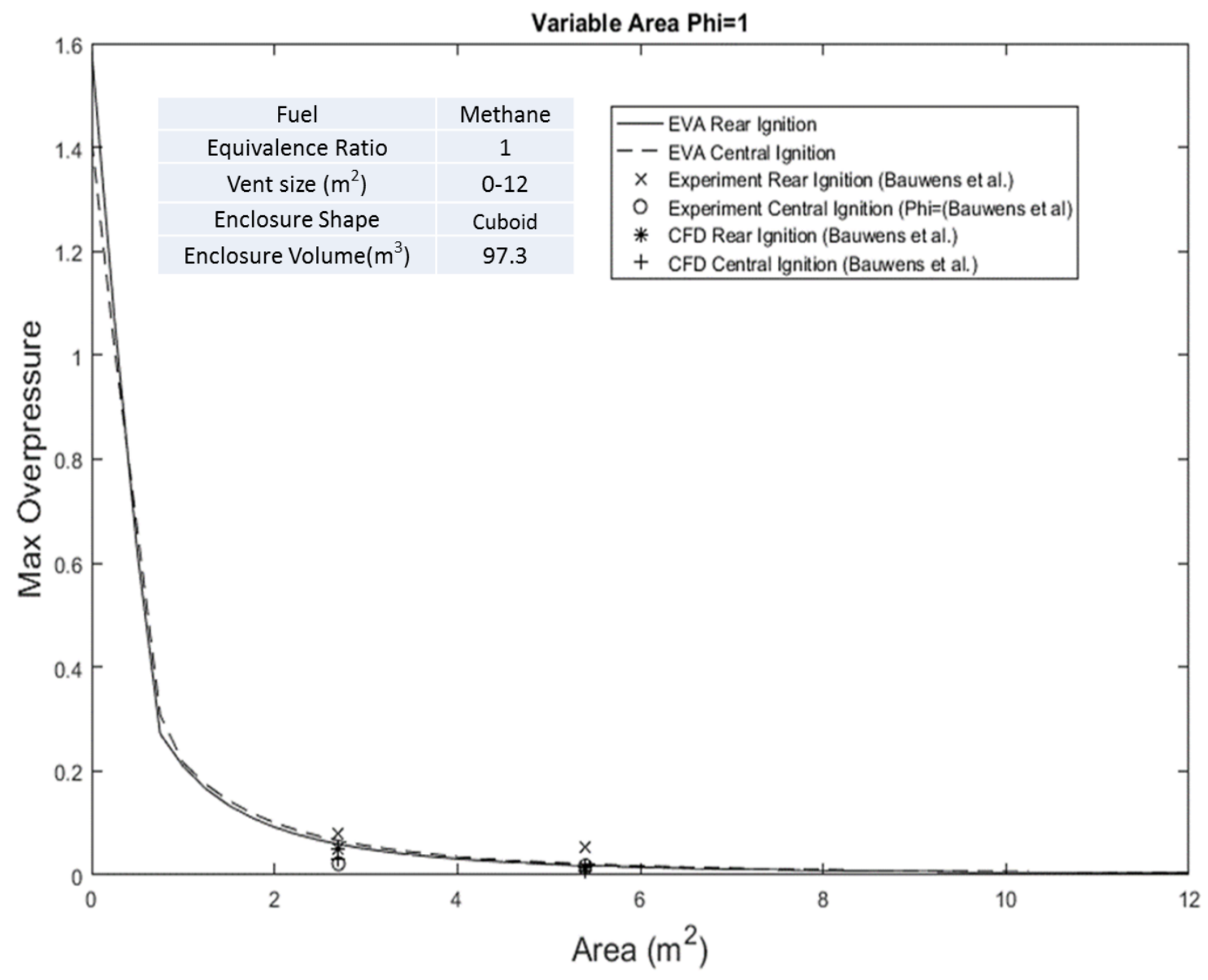

Figure 21- Parametric study of maximum overpressure, where area is varied in the range of 0-12 $\mathbf{m}^{2}$

Figure 22 shows the effects of varying equivalence ratio, are seen to be much less consequential than the effects of vent size. The error in the results when compared to the experimental data is therefore much more visible. It can also be seen, however, that these results are more accurate than the CFD model. This plot was completed for equivalence ratios varying from $0.7-1.2$ and a vent size of $5.4 \mathrm{~m}^{2}$ for a $93.7 \mathrm{~m}^{3}$ enclosure. 


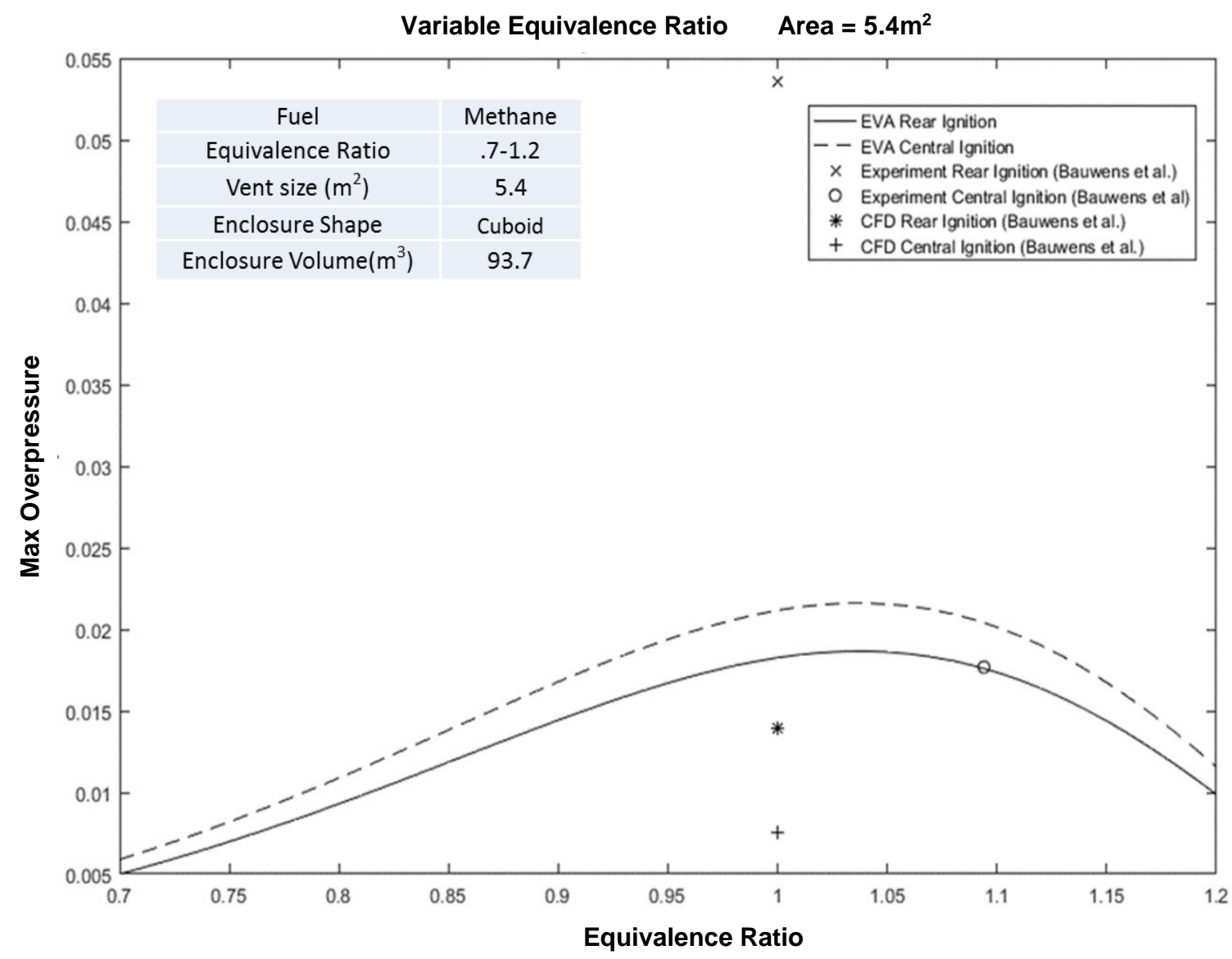

Figure 22- Parametric study of maximum overpressure for equivalence ratio in the range of 0.7-1.2 


\section{Conclusion}

The development of the EVA has been based on the study (Wilkin \& Mulpuru, 1982), which, in turn, was inspired by the work (Bradley \& Mitcheson, 1978a). Prior to the current work, the EVA was improved and developed by Sezer et al. (2016) and Ugarte et al. (2016). The goal of this thesis is to expand on these previous works by improving the EVA and comparing its results to the experimental data. This is done by adding a term to approximate various venting pressures. The results from this were compared to experimental data from (Bao, et al., 2016). Then the simulations and experiments of (Bauwens, et al., 2012) were reproduced with the EVA to compare its accuracy to that of a full CFD simulation. Finally, the EVA was used to complete two parametric studies; for the vent area and the equivalency ratio.

It is demonstrated that the EVA can calculate initial pressure spikes with accuracy similar to that of full CFD models. Of the four experiments, the two with rear ignition were more accurately predicted by the EVA. Of the two experiments for centrally ignited geometries, the pressure spike for the $5.4 \mathrm{~m}^{2}$ vent is predicted much more accurately by the EVA. However, the $2.7 \mathrm{~m}^{2}$ vent geometry is substantially overestimated by the EVA such that the CFD is more accurate in that case.

This can be considered as success as the EVA requires significantly less computer power than typical CFD models. It is also reasonably simple to learn and adapt the EVA to various situations depending on the situation. In particular, not only can the input parameters be quickly changed, but the code can be modified and understood easily. In contrast, CFD models are often proprietary such that the code cannot be modified, which brings some limitations.

The significant reduction in required computing power yields several advantages. First, and foremost, this allows the data to be obtained quickly. Second, the risk of losing time to running simulations with incorrect inputs is reduced. Finally, it allows parametric studies to be completed easily. The parametric studies of this thesis, Figs. 21, 22, show the vent area required to make an explosion survivable, as well as the most dangerous equivalence ratio. This sort of calculation would be prohibitively expensive for a full CFD model.

However, the simplicity of the model also has noticeable limitations. The experimental results for centrally ignited geometries shows large second pressure spikes. This is not calculated 
by the EVA model, even though these spikes are larger than the initial spikes, because of the complex interactions that cause the effects which are not considered by the EVA. These are considered by the CFD model, thereby allowing it to calculate this spike.

With the potential use of the EVA being in fire safety and building design, the model should be easy to use and modify. More importantly, however, this means that the model must be accurate for all geometries. While the version presented in this thesis does not provide accurate predictions of the maximum pressure spike, it does predict the initial stages of the process well. This program will continue to be upgraded so that it eventually will be a reliable resource.

Two future modifications will greatly improve the accuracy of this model and its ability to predict the second pressure spike. First, the equations of shape may be improved to allow a more accurate burning rate to be calculated at the late stages of burning, when the shape becomes more complex. This will allow for the reduction in pressure that is seen at this point in the experiments to be calculated. Additionally, acoustic effects may be considered. While the acoustic oscillations have an effect on the maximum pressure spike, a more consequential result is the increased burning rate caused when the acoustic effects corrugate the flame front. If a reliable term to approximate this increase is found and implemented, then accuracy of the model could be greatly improved without significant increases in required computing time. 


\section{References}

Akram, M., Saxena, P. \& Kumar, S., 2013. Laminar Burning Velocity of Methane-Air Mixtures at Elevated Temperatures. Energy and Fuels, Volume 27, pp. 3460-3466.

Bao, Q., Fang, Q., Zhang, Y., Chen, L., Yang, S. \& Li, Z., 2016. Effects of Gas Concentration and Venting Pressure on Overpressure. Fuel, Volume 175, pp. 40-48.

Bauwens, C., Chao, J. \& Dorofeev, S., 2012. Effect of Hydrogen Concentration on Vented Explosion Overpressures from Lean Hydrogen-Air Deflagrations. International Journal of Hydrogen Energy, Volume 37, pp. 17599-17605.

Bauwens, C.R., Chaffee, J. \& Dorofeev, S., 2008. Experimental and Numerical Study of Methane-air Deflagrations in a Vented Enclosure. Fire Safety Science, Volume 9, pp. 1043-1054.

Biello, D., 2011. Partial Meltdowns Led to Hydrogen Explosions at Fukushima Nuclear Power Plant. [Online]

Available at: http://www.scientificamerican.com/article/partial-meltdowns-hydrogen-explosions-atfukushima-nuclear-power-plant/

Bradley, D. \& Mitcheson, A., 1976. Mathematical Soulitions for Explosions in Spherical Vessels. Combustion and Flame, Volume 26, pp. 201-217.

Bradley, D. \& Mitcheson, A., 1978a. The Venting of Gaseous Explosions in Spherical Vessels. I-Theory. Combustion and Flame, Volume 32, pp. 221-236.

Bradley, D. \& Mitcheson, A., 1978b. The Venting of Gaseous Explosions in Spherical Vessels. II-Theory and Experiment. Combustion and Flame, Volume 32, pp. 237-255.

British Standards Institution, 1964. Measurement of Fluid Flow in Pipes. Part 1 Orifice Plates, Nozzles and Venturi Tubes. London: British Standards House.

Cooper, M.G. \& FairWeather, M., 1986. On the Mechanisms od Pressure Generation in Vented Explosions. Combustion and Flame, Volume 65, pp. 1-14.

Cousins, E.W. \& Cotton, P., 1951. Design Closed Vessels to Withstand Internal Explosions. Chemical Engineering, Volume 58, p. 113.

Cubbage, P. \& Marshall, M., 1973. Pressures Generated by Explosions of Gas-Air Mixtures in Vented Enclosures. Institution of Gas Engineers, Communication, p. 926.

Cubbage, P. \& Marshall, M., 1974. Explosion Relief Protection for Industrial Plant of Intermediate Strength. I Chem. E., Volume 39A, pp. 196-210.

Davy, H., 1815. On the Fire-Damp of Coal Mines, London: The Royal Society Publishing.

Drell, I.L. \& Belles, F.E., 1958. Survey of Hydrogen Combustion Properties, Cleveland: Lewis Flight Propulsion Laboratory.

Dryden, H. L., 1943. A Review of the Statistical Theory of Turbulence. Quarterly of Applied Mathematics, Volume 1, pp. 7-42. 
Fox News, 2015. At least 19 injured, 4 critically, in NYC building explosion. [Online]

Available at: http://www.foxnews.com/us/2015/03/27/new-york-city-building-collapse.html

Gordon, S. \& McBride, B.J., 1996. Chemical Equilibrium with Applications, Cleveland, OH 44135: National Aeronautics and Space Administration, Lewis Research Center.

Haywood, R. W., 1968. Thermodynamic Tables in SI Units. New York: Cambridge University Press.

Heimel, S., 1957. Effect of Initial Mixture-Temperature on Burning Velocity of Hydrogen-Air Mixtures with Preheating and Simulated Preburning, Cleveland, $\mathrm{OH}$ : National Advisory Committee for aeronautics.

Liu, D. \& MacFarlane, R., 1981. Studies in Hydrogen Combustion Using Open Burners, Part 4, : Whiteshell Nuclear Research Establishment Unpublished Report.

Mayhew, Y. \& Rogers, G., 1971. Thermodynamic and Transport Properties of Fluids. Oxford: Blackwell.

Metghalchi, M. \& Keck, J., 1980. Laminar Burning Velocity of Propane-Air Mixtures at High Temperature and Pressure. Combustion and Flame, Volume 38, pp. 143-154.

Palmer, K., 1956. Explosion Protection of a Dust Extraction System. Jounral of the Institute of Fuel, Volume 29, p. 293.

Pasman, H., Groothuisen, T. \& Gooijer, P., 1974. Design of pressure relief vents. In: Loss Prevention and Safety Promotion in the Process Industries. New York, pp. 185-189.

Sezer, H., Akkerman, V., Ugarte, O. J. \& Rangwala, A. S., 2016. Methane- and Propane-Induced Explosions in Vented Enclosures, $40^{\text {th }}$ Technical Meeting of the Eastern States Section of the Combustion Institute, Princeton, NJ, USA, March 13-16, 2016.

Stone, R., Clarke, A. \& Beckwith, P., 1998. Correlations for the Laminar-Burning Velocity of Methane/Diluent/Air Mixtures Obtained in Free-Fall Experiments. Combustion and Flame, Volume 114, pp. 546-555.

Straumann, W., 1965. Sizing of Pressure Relief Openings Against Explosions in Chemical Apparatus. Chemical Engineering Technology, Volume 37, pp. 306-316.

Strehlow, R.A., 1979. The Blast Wave from Deflagrative Explosions, an Acoustic Approach: Ft. Belvoir Defense Technical Information Center.

Travnikov, O.Y., Bychkov, V. \& Liberman, M., 2000. Numerical Studies of Flames in Wide Tubes: Stability Limits of Curved Stationary Flames. Physical Review E, Volume 61, pp. 468-474.

Ugarte, O. J., Akkerman, V. \& Rangwala, A. S., 2016. A Computational Platform for Gas Explosion Venting. Process Safety and Environmental Protection, Volume 99, pp. 167-174.

Wilkin, G. \& Mulpuru, S., 1982. A Model for Vented Deflagration of Hydrogen in a Volume. Atomic Energy of Canada Limited. 